\title{
Ueber die Wirkung aseptisch in das Auge eingedrungener Fremdkörper.
}

\author{
Von \\ Dr. E. Landmann \\ in Göttingen.
}

Im Jahre 1830 warf v. Ammon*) die Frage auf, wie die Natur beim Eindringen fremder Körper in die Medien des Auges handle, wenn jene nicht entfernt werden; ob sie dieselben möglichst unsehädlich mache durch Ineapsulation und wie sich dabei der Organismus, das Auge selbst und vorzüglich die Sehkraft verhalte.

Die umfassende Literatur, welche über diesen Gegenstand aufgehäuft ist, beweist, dass die Aufmerksamkeit der Fachmänner ihm seit jener Zeit fortdauernd zugewendet blieb, wie es bei seiner Wichtigkeit und bei der Hänfigkeit der Verletzungen des Auges nicht anders zu erwarten war. Eine Menge einschlägiger Fälle sind mitgetheilt und nach den verschiedensten Gesichtspunkten beleuchtet worden und der Gegenstand ist in trefflichen Arbeiten monographisch behandelt.

Nichtsdestoweniger waren wir bisher nicht im Stande, die Bedingungen anzugeben, von welchen es abhängt, dass

*) Graefe und v. Walthers Journ. d. Chir. u. Augenheilk. Bd. XVII. Heft 3. 
das längere oder kürzere Verweilen eines Fremdkörpers irrs Auge so sehr verschiedene Folgezustände nach sich ziehen kann. Die Beobachtungen ergeben, dass nach einer solehen Verletzung in der Regel acute eitrige Entzündung eintritt, dass diese aber in seltenen Ausnahmefällen ausbleibt und dass zuweilen sogar jede Reizung des verletzten Auges und auch später jede merkliche Gewebsveränderung feblen kann. Im Allgemeinen wurden die deletären Folgen bei ins Ange gedrungenen Fremdkörpern ohne Unterschied diesen selbst als Ursache zugeschrieben und deshalb gemeiniglich alle Falle, in denen fremde Körper, sei es mit totaler oder partieller Erhaltung der Functionstüchtigkeit, sei es mit Verlust derselben aber ohne fortdauernde Entzündung längere Zeit im Auge ertragen wurden, als bemerkenswerthe Ausnahmen, als Curiosa hingestellt, welche zu den Frfahrungen über den gewöhnlichen Verlauf solcher Verletzungen in grellem Contrast ständen.

Wenn eine Deutung des längeren Verweilens von Fremdkörpern im Auge ohne functionelle oder materielle Störungen des letzteren versucht wurde, so pflegte man dafür durchweg die Annahme einer individuell geringeren Vulnerabilität der Gewebe, eine Toleranz mancher Augen gegen die Einwirkung äusserer Schädlichkeiten heranzuziehen und hielt sie zur Erklärung für genügend. Dass. diese Ansicht unhaltbar ist, bedarf wohl heut zu Tage nicht mehr einer ausführlichen Erörterung; wenn von zwei Fällen, die in Bezug auf die Art der Verletzung, die Grösse, Form und Natur des Fremdkörpers völlig gleichartig sind, in dem einen die traurigsten Folgen für das Auge eintreten, in dem anderen völlig ausbleiben, so geht dies weit über die Grenzen individueller Reizbarkeitsunterschiede hinaus, und wir müssen nothwendig eine andere Ursache dieser Ungleichheit der Folgezustände voraussetzen. Wir brauchen nach einer solchen auch nicht weit zu suchen; die Richtung, in welcher wir die Erklärung 
finden müssen, ist uns gegeben, seitdem die Kenntniss der Folgen, welche die Wundinfection nach sich zieht, Theorie wie Praxis der traumatischen Entzündungen von Grund aus umgestaltet hat.

Die Berucksichtigung des Umstandes, dass in der Mehrzahl der penetrirenden Verletzungen des Auges, insbesondere mit Zurückbleiben eines Fremdkörpers, gleichzeitig auch eine Infection der betroffenen Theile durch Keime niederer Organismen stattfindet, dass diese aber in manchen Fällen ausbleiben kann, erklärt allein die grossen Verschiedenheiten des klinischen Verlaufs, die uns bei diesen Verletzungen entgegentreten.

Von diesem Gesichtspunkt ausgebend, hat Herr Prof. Leber unternommen, die Folgen des Verweilens verschiedener Fremdkörper im Inneren des Auges durch Versuche an Thieren genauer zu erforschen, und ist dabei zu Ergebnissen gelangt, welche einerseits die auf Grund der Infectionstheorie gehegten Erwartungen vollkommen bestätigt, andererseits unsere Kenntnisse über die Wirkungen, welche die verschiedenen Fremdkörper an und für sich hervorbringen, nicht unwesentlich erweitert haben. Bisher liegt über die Ergebnisse dieser Versuche nur eine summarische Mittheilung in einem auf dem internationalen medicinischen Congress zu London 1881 gehaltenen Vortrag *) vor, aus welchem wir das Folgende entnehmen; Herr Prof. Leber beabsichtigt aber, demnächst seine Beobachtungen ausfuhrlicher za veröfentlichen. Die Schlüsse, zu welchen er durch seine Versuche gelangt ist, sind im Wesentlichen folgende:

1. Die blosse Gegenwart eines reinen $d$. h. nicht mit entwicklungsfähigen Keimen niederer Organismen behafteten und chemisch indifferenten Fremd-

*) Th. Tieber, Ueber die Wirkung von Fremdkörpern im Inneren des Anges. Transact. of the internat. med. Congress. Lundon 1881. Vol. III. p. 15-19. 
körpers im Inneren des Auges ruft keinerlei Entzündung hervor.

2. Aseptische Fremdkörper aus Metallen, welche im Auge der Oxydation unterliegen, bewirken keine eitrige Entzündung, können aber schwere Folgen nach sich ziehen. Sie thun dies besonders nach Einführung in den Glaskörper, wo sie bei hinreichender Grösse eine acute Atrophie und $\mathrm{Ab}$ lösung der Netzhaut mit eigenthümlichen histologischen Veränderungen hervorrufen, welche Processe der chemischen Einwirkung jener Metalle zuzuschreiben sind.

3. Eitrige Entzündung des Auges nach Verletzungen entsteht immer bei Vorhandensein der Keime gewisser niederer Organismen; es ist dies die einzige in praktischer Hinsicht wesentlich in Betraeht kommende Ursache; eitrige Entzündung kann allerdings auch durch rein chemische Reize entstehen, die aber im gewöhnlichen Leben, bei Aussehluss niederer Organismen, nicht vorzukommen pflegen.

4. Die eitrige Entzündung, die durch das Wachsthum von Mikrobien erzeugt wird, entsteht dadureh, dass die letzteren durch ihren Lebensprocess gewisse entzündungserregende, chemische Substanzen hervorbringen. In ähnlicher Weise ist auch die Wirkung gewisser thierischer Parasiten z. B. des Cysticercus cellulosae, der als Fremdkörper im Inneren des Auges Entzündung hervorruft, zu erklären.

Da die parasitäre Entzündungstheorie auch für den Menschen anerkannte Geltung besitzt, so ist es gewiss gerechtfertigt, die Ergebnisse dieser Versuche auf das mensehliche Auge $\mathrm{zu}$ übertragen und wenigstens in ihren Grundzügen für gültig zu erachten, Zudem liegt wenigstens 
für den ersten Satz ein stricter Beweis auch am mensehlichen Auge vor in der bekannten Drainage des Auges mit Golddraht nach v. Wecker, die für uns in theoretischer Beziehung geradezu den Werth des Experimentes besitzt. Wochenlanges Liegenbleiben von Golddrähten in den Geweben und Räumen des Auges bewirkt keinerlei Entzündung und wenn diese einmal ausnahmsweise erfolgt so dürfen wir sie ungezwungen dem Hinzutreten einer Infection des Stichcanales zur Last legen.

Mit der Ansicht, dass die dem Eindringen eines Fremdkörpers in das Innere des Auges nachfolgende eitrige Entzündung infectiösen Ursprunges sei, vereinigen sich diepraktischen Erfahrungen in ganz befriedigender Weise. Dass bei den meisten derartigen Verletzungen eitrige Entzündung auftritt und somit Infection anzunehmen ist, hat gewiss nichts Auffallendes, wenn man die Verhältnisse berücksichtigt, unter denen solche Verletzungen gewöhnlich stattfinden; ebenso sicher ist jedoch anzunehmen, dass hieund da einmal ein Fremdkörper frei von Infectionskeimen ins Auge gelangen kann, und diese Möglichkeit muss eben für alle Fälle in Anspruch genommen werden, in welchen eitrige Entzündung ausbleibt.

Es erhebt sich nun die Frage, welches die Schicksale: des Auges und seiner einzelnen Theile im letzteren Falle sein werden, wenn der ins Auge gelangte Fremdkörperzwar aseptisch ist, aber in anderer Weise eine Quelle von Reizung oder sonstigen abnormen Vorgängen für dasselbe abgiebt, insbesondere, wenn er mechanisch oder chemisch. auf dessen Gewebe einwirkt. Es ist von grossem, nicht nur theoretischem, sondern auch praktischem Interesse, diesen Folgezuständen nachzugehen und zu ermitteln, wie weit dieselben beim Menschen mit den Beobachtungen derThierversuche übereinstimmen.

Man konnte erwarten, durch genaue Durchmusterung. der in der Literatur vorhandenen Falle hierüber einigen. 
Aufschluss zu gewinnen, und durch Zusammenstellung derselben nach bestimmten Gesichtspunkten den Weg für weitere Fortschritte unserer Kenntnisse auf diesem Gebiet zu ebnen. Von Herm Professor Leber auf diese Aufgabe hingewiesen, habe ich versucht, das umfangreiche Material der Fachliteratur dafur zu verwerthen und konnte auch eine Anzahl netierer Beobachtungen aus der hiesigen Augenklinik benutzen, welche mir von Herrn Prof. Leber zu diesem Zwecke freundlichst überlassen wurden.

Es schien nicht überflüssig, in die Zusammenstellung diejenigen Fälle mitaufzunehmen, in welchen auch nach längerer Zeit jede Reaction ausblieb, einmal um diese Möglichkeit überhaupt durch eine Reihe von Beispielen sicher festzustellen, und dann um die Bedingungen ihres Eintretens möglichst zu erforschen. Dagegen mussten alle diejenigen Fälle ausgeschlossen bleiben, in welchen die Verletzung sogleich von stärkerer, namentlich eitriger Entzündung gefolgt war, welche, durch Infection entstanden, die etwaige Wirkung des Fremdkörpers verdecken musste. Andererseits, wenn eine anfangs nur mässige Entzündung später zurückging und trotzdem der Fremdkörper dauernd im Auge vertragen wurde, so konnten auch solche Fille unter Cmständen für unsere Zwecke verwerthbar sein.

In Bezug auf den Sitz sind im Nachstehenden nm* die Fälle aufgenommen worden, wo der Fremdkörper in der vorderen Kammer, auf der Iris, in der Linsenkapsel nach resorbirter Cataract, dem Corpus ciliare, dem Glaskörper und in der hinteren Bulbuswand gelagert war. Falle von Sitz in der Cornea oder in der Linse sind nicht berücksichtigt; erstere deshalb, weil bei der oberflächlichen Lage der Wunde diese zu leicht einer von aussen kommenden Infection ausgesetzt ist, und auch, weil ein längeres Verweilen eines Corpus alienum im Gewebe der Cornea selten beobachtet wird, da die Therapie unmittelbar eingreifen kann. Für die fremden Körper in der Linse 
ist beobachtet und längst bekannt, dass sie als solehe nur Cataract hervorrufen, die allerdings bei oxydationsfähigen Metallen durch Aufnahme von Oxydpartikelchen eine eigenthümliche Farbe darbieten kann, abgesehen von den Folgen einer etwaigen Infection und von den durch Linsenquellung hervorgerufenen secundären Störungen. Ist die Cataract zur Resorption gekommen, und steckt der Fremdkörper in den Kapselresten, so sind natürlich die Verhältnisse die gleichen wie bei primärem Sitz desselben in der vorderen Kammer.

Bei dem grossen Umfang des literarischen Materials mag mir gewiss mancher prägnante Fall entgangen sein, zumal aus weniger zugänglichen Quellen, doch kommt es ja für den Zweck der Arbeit weniger darauf an, in dieser Hinsicht ganz erschöpfend zu sein. Ich bemerke noch, dass ich die fremden Beobachtungen möglichst nach dem Original und nur in unwesentlichen Punkten verkürzt wiedergegeben habe; nur wo mir die Originalmittheilung nicht zugänglich war, habe ich mich mit einem Referat über dieselbe begnügt.

I.

Ich stelle nun zunächst diejenigen Beobachtungen zusammen, in welchen der im Auge zurückgebliebene Fremdkörper, in chemischer Beziehung völlig indifferent, gar keine oder höchstens eine mechanische Wirkung durch sein Verweilen im Auge ausüben konnte.

Hierher gehören Stein-, Glas-, Holzfragmente, Cilien, Golddraht und wahrscheinlich auch von den Metallen das Blei, selbstverständlich so weit sie frei von Keimen niederer Organismen sind. Fälle, wo Stücke edler Metalle zufällig in das Auge eingedrungen waren, sind nur wenige bekannt; nicht selten hingegen sind Verletzungen durch im Auge zurückbleibende Bleistücke, welche wegen des 
höchst auffälligen Ausbleibens von Reizerscheinungen in diesen Abschnitt aufgenommen sind. Auf die Erklärung dieses Verhaltens werden wir weiter unten eingehen.

A.

Chemisch indifferente Fremdkörper in der vorderen Augenkammer oder in den sie umgebenden Theilen.

Fs sind zunächst eine Reihe von Fällen anzuführen, in welchen der fremde Körper, sei es nach längerer, sei es nach kürzerer Zeit überhaupt keinerlei Reizerscheinungen hervorgerufen hatte, abgesehen von den directen Folgen: der Verletzung selbst.

1. How ${ }^{*}$ ) giebt an, dass er nach einer Verletzung ein Pulverkorn vollkommen reizlos auf der Iris habe sitzen sehen.

2. Rognetta beobachtete, wie Zander und Geissler***). mittheilen, acht Tage lang ein erbsengrosses Porzellanstück in die vordere Kammer eingelagert, ohne dass dieses auch nur die zur Incapsulation nöthige Entzündung verursachte.

3. Richards on ***): Einem Soldaten war vor 46 Jahren durch Zerplitterung eines Baumes durch eine Kanonenkugel das rechte Auge zerstort und dabei gleichzeitig in das linke $3 \mathrm{Hol}$ z splitterchen eingetrieben worden. Nach 4 Tagen sah Patient wieder und war seitdem frei von Entzündung. In der vorderen Kammer - die Iris war bis auf einen Streifen reducirt - lagen drei weissliche Körperchen von einer zarten Haut umkleidet und mit einigen Pigmentkörnchen bestreut.

4. Laws on $)$ ): J. L., $67 \mathrm{Jahr}$, stellt sich vor, nachdem er 7 Wochen zuror beim Beschneiden einer Hecke durch

*) Howe, The Buffalo med. et surg. Journ. Nov. 1879.

**) Zander und Geissler, Die Verletzungen des Auges. 1864, p. 170.

***) Richardson, Dubl. Journ. XXVIII, p. 320. Citirt bei Zander u. Geissler, p. 171.

f) Lawson, Ophth. Hosp. Rep. VJ. 1867, p. 38. 
einen Dorn am rechten Auge verwundet worden war. Keine wesentlichen Beschwerden und deshalb keine $\mathrm{Be}$ handlung. Der Dorn hatte die Cornea durchdrungen, und zwar so, dass das innere Ende halb in die vordere Kammer vorragte, während das äussere halb in der Cornea steckte. Der etwas gequollene Dorn wurde extrahirt.

Bei Gelegenheit operativer Eingriffe ereignet es sich nicht selten, dass, während die Operation den gewünschten Erfolg hat, dem Auge absichtslos ein Fremakörper eingefügt wird. Als derartige sind besonders die abgeschnittenen Cilien beobachtet, welche in den meisten Fällen gut vom Auge vertragen werden. Es liegt auf der Hand, dass nur die vordere Kammer und Iris Sitz derselben sein kann. In ähnlicher Weise können Cilien auch bei zu= fâlligen Verletzungen in's Auge gelangen.

5. Pagenstecher (bei Zander und Geissler) sah eine Cilie, welehe reizlos 10 Jahre lang in der vorderen Kammer gelegen hatte.

6. v. Graefe *) beobachtete ebenda Cilien, welche nach zwei Vonaten noeh keine Funetionsstörungen gemacht hatten.

7. Fränkel**) berichtet über eine Cilie, welche nach einer Verletzung im Auge zurückgeblieben war und nahe dem Ciliarrande der Iris im inneren oberen Quadranten ohne jeden Reizzustand 4 Wochen nach der Verletzung sass.

8. Pufahl ***): Vor acht Tagen hatte eine Verletzung durch Anprallen eines Eisenstückes an das linke Auge stattgefunden: vom Rande eines in die schräge Cornealwunde eingeheilten Iriszipfels krümmte sich eine Cilie bogenförmig vor der Pupille empor, eine zweite spannte sich hinter der Iris aus und war nur zum Theil innerhalb der Pupille sichtbar. Nach künstlicher Erweiterung derselben hatte sich die erste Cilie parallel dem unteren Ciliarrande gesenkt, die zweite sah man mit einer hinteren Synechie verbunden. Nach und nach löste sich.

*) Arch. f. Ophth. VII. 2. p. 134.

**) Zehender, Monatsbl. 1878. XVI. p. 127.

秘) Deutsche Zeitschr. f. prakt. Med. No. 31 .

v. Graefe's Archiv für Ophthalmologie, Xxvrrr. 2. 
diese und erst an 18. Tage nach der Verletzung trat ein grösserer Reizzustand ein, der sich aber nach einer Woche wieder verlor. Die untere Cilie blieb nuverschieblich auf der Tris liegen, die obere war mit dem Pupillarrand rerbunden, ihr anderes Ende ragte frei ror der Pupille nach vorn herab.

9. Friedinger*): Ein glühender Eisensplitter springt gegen den Cornealrand; Tris zerrissen, prolabirt. Hyphama. Nach Resorption desselben wurde eine Cilie in der rorderen Kammer sichtbar. Dieselbe ist bisher 4 Jahre lang ohne Schadeu liegen geblieben.

10. Nach Rothmund**) sass ein Büschel ron Cilien 14 Tage lang in der vorderen Kammer, welches erst für eine vordere Synechie gehalten wurde und von einen Winkel der Cornealwunde bis zum Pupillarrand verlief. Entfernung. -

11. In der Göttinger Klinik kam folgender Fall zur Beobachtung:

82j. Mann. Modif. Linearextraction einer reifen Cataract, viel Blut in die vordere Kammor ausgetreten, das sich aber bei der leicht und vollständig erfolgenden Linsenentbindung grössentheils wieder entleert. Ziemlich grosser Conjunctivallappen. Heilung völlig normal, Pupille rein und schwarz. Etwa 2 Jahre nach der Operation, wo sich Patient wegen eines sehr zarten Nachstaares wieder vorstellt, findet sich eine Cilie, die rom äusseren Theil der Operationsnarbe in die vordere Kammer frei hineinragt ohne jede Spur von Reizung.

Dass die Cilien sich so indifferent verhalten, während doeh sonst die Haare oft Träger von Infektionskeimen werden, mag sich daraus erklären, dass diese Keime hier sich weniger ungestört ansiedeln können. Die mechanische Einwirlrung der Cilien kann nicht bedeutend sein, da sie meist flach aufliegen und bei ihrem geringen Gewicht und ihrer Biegsamkeit den Bewegungen der Iris wohl kaum einen Widerstand entgegen setzen.

*) Wiener med. Wochenschr. XXVIrr. 1878.

*) Klin. Monatsbl. f. Augenheilk. X., p. 189. 
Es ist aber bekannt, dass in das Auge gelangte Cilien demselben in anderer Weise schädlich werden können, wenn sie Partikel lebensfähiger Epidermis mit sich führen, welche auf der Iris sich zu Epidermidomen entwickeln, wie dies von Rothmund und Anderen beobachtet und von Schwenninger*) experimentell verfolgt ist.

Edle Metalle sind nur selten als Fremdkörper im Auge beobachtet, doch sind einzelne Beispiele in der Literatur verzeichnet, wo Stïcke Golddraht in das Auge eingedrungen waren:

12. Stellwag ${ }^{* * *}$ ) berichtet von einem Goldspinner, dem beim Abhaspeln ein Stück Golddraht von $3-4 \mathrm{~mm}$ Länge durch die Cornea in die vordere Augenkammer eingedrungen war, in welcher es zusammengelrümmt lag, während das Ende kaum über die Oberfläche der Hornhant hervorragte. Nach 2 Tagen war die Hornhaut noch vollkommen klar und glänzend, ohne Spur von Wundinfiltration, nur die Conjunctiva stark injicirt und geschwellt. Das Ende des Drahtes liess sich eben noch mit der Pincette fassen und der Draht extrahiren, woranf am andern Tag die Wunde spurlos vernarbt war.

Wenn in einem anderen Falle gleicher Art stärkere und anhaltende Reizung beobachtet worden ist, so kann diese sehr wohl dadurch bedingt gewesen sein, dass die Verletzung keine reine war; die günstige Wirkung der Extraction kann durch die Paracentese bedingt gewesen sein.

13. Fall von Wardrop***): Bei einem Manne wurde an der Schläfenseite der Hornhaut ein trüber Punkt wahrgenommen, an welchem die verzogene Pupille àdhärirte. Heftige Conjunctivitis and starke Lichtscheu. 14 Wochen vorher war dem Kranken ein Stück feinen Golddrahts in das Auge

*) Sc hwenninger, Arch. f. experim. Pathol. II. S. 387.

**k Stellwag, Die Ophthalmologie vom naturwiss. Standpunkt I. S. 327, Note 93 (1853).

****) Wardrop, Lancet X. p. 475. 1826. Nach Zander und Geissler loc. cit. S. 133. 
gesprungen. 3 Tage nachher stellte sich Entzündung ein, welche 5 Wochen lang sehr heftig war, aber dam etwas mässiger wurde. $\mathrm{Da}$ in dem grauen Punkte ein Ende von Golddraht sichtbar war, so wurde dieses mit einer Pincette gefasst und ein $3 \mathrm{~mm}$ langes Stäck ausgezogen, wobei Kammerwasser abfloss. Die Heilung gelang nunmehr rasch und vollkommen.

Hieran reihen sich die Beobachtungen über reizlos im Auge vertragene Bleis tücke:

14. Ein Schrotkorn sah Cooper*) ohne Entzündung in die vordere Kammer eingelagert.

15. Dr. Salomon**) beschreibt eine Augenverletzung durch einen Schrotschuss (Korn No. 5), wo das Sehrotkorn Selera und Iris durchdrang und dann in der vorderen Kammer, ein wenig nach dem äusseren Augenwinkel hin, liegen blieb. Hier wurde es bald durch plastisches Exsudat abgekapselt und blieb 5 Jahre hindurch, ohne dem Genesenen ein Gefühl von Sehmerz oder Besehwerde zu erregen oder einen schädlichen Einfluss auf das Sehvermögen zu veranlassen, liegen.

Ueber eine Schrotverletzung, welche entzündliche Symptome im Gefolge hatte, berichtet

16. Graefe (Vater)** Einem Fischer war ein Schrotkorn ins Auge geflogen; es folgte Entzündung und dann Resorption der Linse, worauf der Fremdkörper in die vordere Kammer vorfiel und dort von Flocken umgeben 6 Jahre lang ohne den Augapfel in seiner Integrität und Funktion zu stören, liegen blieb.

Die Entzündung, welche, wie es in diesem Falle heisst, der Verletzung folgte, kann nur unerbeblich gewesen sein, da sonst eine Resorption der Linse nicht hätte eintreten können. Die Erseheinungen sind wohl mehr als eine ron der Verletzung selbst abhängige blosse Reizung zu betrachten, da der in die vordere Kammer gefallene Fremd-

*) Nach Zander u. Geisslex loc. cit. S. 170 .

**) v. Ammon's Zeitschr. f. Ophth. I. S. 336 (1830).

***) Graefe u. Walthers Joum. 14, p. 157. 
Körper daselbst weiterhin ohne jede Störung ertragen wurde.

Dasselbe ist auch in dem folgenden Fall von Stöber*) anzunehmen, in welchem ein Schrothorn die vordere Kammer durchflogen zu haben scheint, um unter der Bindehaut stecken zu bleiben.

17. J. M., 7 Jahre alt, wurde von einem Flintenschuss ins rechte Ange getroffen. Schwellung des ganzen Gesichts, so dass die Augen nicht geöffnet werden konnten. Als dies möglich war, erschien das Auge in seiner ganzen Ausdehnung geröthet und war blind. Nach und nach verschwand die Röthe, und man bemerkte einen weissen Fleck, der die Mitte der Iris und Pupille verdeckte. Fast ein Jahr nachher zeigte sich ein Fremdkörper auf dem unteren Theil des Augapfels. In dieser Zeit sah Stöber den Patienten; er fand ein Schrotkorn zwischen Conjunctiva und Selera an der unteren änsseren Partie des Bulbus sitzend und leicht nach verschiodenen Richtungen zu verschieben. Selera und Conjunctiva normal. Die Cornea zeigte einen länglichen Fleck, $1 / 2$ " gross, welcher schräg von aussen oben nach innen unten gerichtet war und der Iris adhärirte. Am unteren änsseren Cornealrande sah man einen zweiten Fleck, welcher von einer Narbe herzurühren schien. Die benachbarte Sclera war von leicht geschwellter Conjunctiva bedeckt. Der Rest der Cornea war klar und der Theil zwischen den Leukomen hatte sich nach und nach aufgehellt. Die blaue Iris zeigte an der unteren inneren Partie nahe dem 2. Cornealfleck eine runde, wie zerrissene Oeffnung; welche ein Fremdlörper gemacht haben musste. Pupille unbeweglich, Grund des Auges schwarz, Sehschärfe auf schwachen Lichtschein reducirt. Extraction verweigert.

Im Mai 1835, nach 4 Jahren, sah Stöber den Patienten wieder. Fremdkörper noch immer am selben Platz. Cornealfecke vermindert, Iris noch adhärent, und es

*) Arch méd. de Strasbourg août 1835, p. 417, reproducirt in Sengel, Des corps etrangers de la conj. et du globe oculaire. Thèse. Strasbourg 1859, p. 47. 
flottirte ein schmaler Faden, dem Rand der Pupille aufsitzend in der vorderen Kammer. Pupille $z \mathrm{u}^{3 / 4}$ ihrer Ausdehnung normal; die durch den Fremdkörper gemachte Deffnung noch vorhanden. Das Sehvermögen hat sich seit einem Jalure stetig verbessert, ist aber schwächer als auf dem anderen Auge.

Der Hergang der Verletzung, über welchen Stöber im Unklaren ist, muss wohl der gewesen sein, dass das Schrotkorn die Hornhaut schräg von aussen oben nach innen unten durchbohrte, dann die Hornhaut an ihrem inneren unteren Rand streifend die Iris und den Randtheil der linse und zuletzt von innen her den Ciliarkorper und die Sclera durchdrang, um in der letzteren oder unter der Conjunctiva auf dem äusseren unteren Theil der Bulbusoberfläche stecken zu bleiben. Die Besserung des Sehvermögens erklärt sich durch Resorption der traumatisehen Cataract.

Dass das Verweilen von Bleistücken ohne schädliche Folgen ist, kann wohl dadurch erklärt werden, dass das Blei von alkalischen, schwach kohlensäurehaltigen Flüssigkeiten, wie die des Auges, so gut wie gar nicht angegriffen wird, indem es sich mit einer dünnen Schicht von Bleicarbonat bedeckt, welches die weitere Einwirkung der Kohlensäure abhält.

Auch in manchen Fallen von Steinsplittern in der vorderen Kammer handelt es sich nur um eine mehr vorübergehende Reizung durch den Eingriff der Verletzung selbst, und wurde weiterhin der Fremdkörper ohne Beschwerde ertragen.

18. v. Wecker*): Steinfragment aus der vorderen Kammer entfernt, nachdem dasselbe 14 Jahre darin verweilt hatte.

22jähr. Arbeiter; Verletzung im Alter von 8 Jahren durch einen Steinsplitter, darauf leichte Entzündung und Verlust des Sehvermögens bis anf quantitative Lichtempfindung. Die Untersuchung ergiebt eine $2 \mathrm{~mm}$ lange

*) Gaz. des Hopit. 1866. No. 92. 
Hornhautnarbe, traumatische Cataract mit Kapselve:dickung und am oberen Pupillarrand ein kleines Steinfragment, das uneingekapselt an diesem sowie an dem Rande der Kapseltrübung angeheftet war. Die Entfernung des $2 \mathrm{~mm}$ langen Basaltstückehens gelang leicht und durch das gleichzeitig angelegte Colobom konnte Patient, da die Trübung auf den centralen Theil der Linse beschränkt war, Finger auf 2 ' Entfernung erkennen.

In einem Fail von Jeaffreson*) wurde sogar der Steinsplitter, ohne Entzündung erregt zu haben, nach einigen Tagen durch die Wunde wieder ausgestossen:

19. Einem Steinarbeiter flog ein Stecknadelknopf grosses Steinstück in's Auge. Wunde am unteren inneren Cornealrand und dahinter ein entsprechendes Loch in der Iris; Medien vollkommen klar, geringer Schmerz; keine Entzündung. - Belladonnaumschlag. - Nacl 4 Tagen kam ein Steinstück spontan durch die Cornealwunde heraus, welche dann heilte. Defect in der Iris blieb sichtbar; Sehvermögen gut.

Andere Male ist nach der gleichen Verletzung stärkere und andauernde Entzündung notirt, welche aber allmälig ganz zurückging, obwohl der Fremdkörper im Auge blieb, mitunter ganz frei und ohne Einkapselung. Die anfängliche Fintzündung kann daher nicht dem Fremdkörper zur Last gelegt werden, sondern würde bei derselben Verletzung auch ohne sein Verbleiben im Auge eingetreten sein; vermuthlich wird sie die Ursache in einer leichten Wundinfection haben, die durch eine reactive Entzündung allmälig überwunden wird.

20. Jeaffreson $\left.* *^{*}\right)$ : Ein alter Mann wurde von einem Steinsplitter am Auge verletzt und hatte viel Schmerz und Fintzündung während einiger Wochen, nach deren $A b$ lauf das Sehvermögen an dem Auge erloschen war.

*) Med. Times a. Gazette 1874, p. 342.

**) Med. Times a. Gazette. 1874, März. 1. 342. 
Auge frei von Injection. Die Pupille war besetzt mit einer dunklen Masse in der Grösse eines Hirsekorns. Wunde der Cornea geheilt and kaum sichtbar. Iris sah gesund aus, konnte jedoch wegen der Befestigung an die obige Masse nicht erweitert werden. Durch einen Randschnitt wurde ein Steinstück extrahirt. Patient ging darauf nach Hause und bei der nächsten Vorstellung bestand ein kleiner Irisprolaps, welcher abgetragen wurde, und jetzt geht es inm gut.

21. Grüllich $*$ ): Ein Steinsplitter flog einem Fabrikanten in's Gesicht (r. Auge). Nach Heilung der äusseren Wunde war das Auge collabirt, und es bestanden bis $5 / 4$ Jahre nach der Verletzung etwas Exophthalmus, anhaltende Schmerzen und Kopfweh. Iris und Cornea nach dem inneren Augenwinkel hin durchtrennt; bedeutende Narbe. Pupille erscheint in Form eines weissen Dreiecks gleich einer Hülle nach vorn gedrängt. Aus der weissen häutigen Hülle wurden 3 Steinsplitter im Gesammtgewicht ron 18 Gran extrahirt.

Wenn ein Fremdkörper mit einem spitzen Ende oder einer scharfen Kante der Iris aufgelagert oder in diese eingespiesst ist, so muss er sie bei ihren Bewegungen mechanisch reizen, was zu Schmerzempfindung Aulass geben wird, die mitunter sehr anhaltend und unerträglich ist und an die sich auch congestive Hyperämie der Iris und entfernterer Theile des Auges anschliessen kann.

Blosse Schmerzen, mehr oder minder rasch vorübergehend, sind in folgenden beiden Fällen von Dornen in der vorderen Kammer beobachtet:

22. Mackenzie**) erzählt einen Fall, wo ein Dorn mit seinem dickeren Ende in der Cornea, mit dem dünneren in der Iris stalk. Die Verletzung hatte 3 Wochen vorher stattgefunden. Hornhautwunde geheilt. Das Auge zeigte keine Entzündung sondern nur leichten Reiz.

*) v. Ammon's Zeitsehr. f. Ophth. I. p. 336.

**) Pract. treat. case 248, p. 394, 4. edit, citirt nach Knapp's Arch. VIII 1879, p. 74. 
23. In der Göttinger Klinik kam folgender Fall zur Beobachtung, der eine 57 jährige Frau C. W. betraf: Am 13. April 1880 war ihr ein Dornzweig gegen das Auge geschlagen; 3 Wochen hinterher habe das Auge stark geschmerzt und sei geschwollen gewesen. Etwa seit dem 12. Mai konnte Patientin das Ange wieder frei offhen, doch klagte sie noch $a b$ and zu über stechende Schmerzen. Kleine Hornhautnarbe von etwas unregelmässiger Gestalt gegenüber dem äusseren inneren Pupillarrand; davon getrennt ein kleines grauliches Pünktchen, dom inneren unteren Pupillarrand gegenüber, offenbar ebenfalls ron der Verletzung herrührend. Am inneren Pupillarrand ein Riss des Sphincter; die übrige Pupille dureh Atropin gleichmässig erweitert, die untere Ecke des Sphincterrisses durch eine feine Synechie fixirt, ausserdem auf der Kapsel zwei kleine Pigmentpünktchen, von gelösten Synechieen herrührend. Auf dem äusseren unteren Theil der Iris, ungefähr dem Ciliarrand parallel, ist die abgebrochene Spitze des Dorns aufgelagert, ca. $1 \mathrm{~mm}$ lang; die Spitze nach innen unten, das stumpfe Ende nach aussen oben gerichtet. Dieselbe liegt vollkommen frei der Iris auf, ohne das mindeste umbüllende Ersudat und ist von dunkelbrauner Farbe.

Patientin wurde regelmässig $3 \mathrm{mal}$ täglich atropinisirt, behauptet aber, noch viel Schmerzen gehabt zu haben. Linse vollstänđig unverletzt. Augenhintergrund zeigt keine Veränderungen.

Anfangs Juni Status idem; keine Ciliarinjection, Pupille weit; Fremdkörper noch immer ganz frei auf der Iris aufgelagert. Patientin klagt über continuirliche Schmerzen, besonders Nachts; vermuthlich liegt eine mechanisehe Reizung durch die Spitze zu Grunde.

Später verloren sich die Schmerzen nach und nach, ohne dass der objective Befund sich änderte, so dass von einer Extraction des Fremdkörpers abgesehen wurde.

Desgleichen berichtet

24. Jüngken *), dass er wiederholt Fälle beobachtet habe, in welchen bei Fremdkörpern auf der Iris die Kranken über äusserst heftige Schmerzen im Auge klagten, be-

*) Die Lehre v. d. Augenkrankh. 3. Aufl. Berlin 1842, p. 564 . 
sonders bei jedem Versuch dasselbe anzustrengen, die nur durch die Entfernung der fremden Körper beseitigt wurden; in anderen Fällen waren die Kranken, abgesehen von einer gewissen Fmpfindlichkeit des Auges, nicht weiter gestört. Die Fremakörper waren kleine Steinfragmente oder Pulverkörner und zeigten sich auf der Iris durch einen zarten häutigen Beschlag fixirt.

Vielleicht gehört hierher auch eine Beobachtung von 25. Jacob*), betreffend ein sehr scharfes, $1 / \pm$ "langes und $1 / 6$ " dickes Steinstuck in der vorderen Kammer, welches erst nach Verlauf von 4 Jahren einen erheblichen Reizzustand bedingte.

Besonders merkwürdig sind die Falle, wo Glasstïckchen viele Jahre lang in der vorderen Kammer verweilten. In einem Falle Critchett's beschränkten sich die Erscheinungen auf etwas Empfindlichkeit des Auges and hie und da wiederkehrende Reizung, die aber nicht zur Exsudation um den stets beweglich bleibenden Fremdkörper führte; in den beiden anderen Fällen waren die Anfälle heftiger, mit lebhaften Schmerzen und starker Lichtscheu verbunden, gingen aber ebenfalls wieder regelmässig zurück. In Jaeger's Fall wurde der Glassplitter eine Zeit lang durch pannöse Hornhauttrübung verdeckt und, während ex anfangs beweglich war, auf der Iris fixirt. Auch in Hirschberg's Fall war der Splitter durch einen Bindegewebsstrang fixirt, aber theilweise frei zu sehen.

26. Critchett**): Einem jungen Farmer war vor 16 Jahren ein kleiner Glassplitter gegen das linke Auge geflogen, der von einem Gläschen kam, welches, in eine Flamme gehalten, explodirte. Leichte, sehr rasch vergehende Entzündung. Patient bemerkte aber seitdem, dass, wenn er den Kopf beim Lesen oder Schreiben nach vorn neigte, sich etwas vors Auge schob und das Sehen störte. Man bemerkte als Ursache einen kleinen Glassplitter auf der

*) Dublin. med. Press 1846, Dec.

**) Ophth. Hosp. Rep. I. p. 264. 
Hinterfläche der Cornea, der beim Aufrichten allmälig sich senkte und im Iriswinkel verschwand. Das Auge war hin und wieder von leichten Entzïndungen heimgesucht und etwas empfindlich. - Hornhautschnitt nahe dem Ciliarrand der Iris. Das Splitterchen musste sich mit dem abfliessenden Kammerwasser entleert haben, da es hinterher nicht mehr im Auge zu entdecken war, und Pationt auch nichts mohr davon spürte, was ein Jahr später bestätigt wurde, wo das Auge sich normal befand.

27. Fall von C. Jaeger, mitgetheilt von Höring. *) Einer 27 jährigen Patientin sprang von einem mit Woingeist gefüllten und ans Feuer gelegten Glaskügelchen, welches platzte, ein Splitter ins linke Ange; heftiger Schmerz. Durch den Versuch, zu extrahiren, wurde der noch in der Cornea sitzende Glassplitter in die vordere Kammer gestossen. Sechs Monate später wurde die bis dahin helle Cornea pannös getrübt und der Splitter konnte nicht mehr gesehen werden. Andanernd heftige Schmerzen. Auf Ruhe ging die Entzundung zuräck, die Cornea hellte sich auf und der Splitter wurde wieder sichtbar; die hochgradigen Schmerzen blieben; ein Arzt wandte ,eitermachende" Mittel an, die dem Auge nicht schadeten, aber auch nicht nützten. Nach 5 Jahren von Jaeger in Wien untersucht, fand sich der dreieckige mit der Basis nach unten, Spitze nach oben liegende Splitter so, dass er bei erweiterter Pupille den unteron Pupillarrand überragte und in dieser Stellung nicht mehr beweglich war. Eine Narbe sass mitten in der Cornea und in deren Umgebung bestand eine Verdunkelung. Sonst keine krankhaften Veränderungen. Bei der Operation mit dem Staarmesser wurde der Splitter nicht gesehen; der Schmerz sistirte und nach Heilung der Wunde war kein Splitter sichtbar. Nach einigen Monaten traten wieder lebhafte Schmerzen im Ange auf; der Splitter wurde nach dem inneren Augenwinkel zu an der Verbindung vou Cornea und Iris bemerkt und drüelte letztere einwärts. Dio Entfernung gelang. Jaeger extrahirte einen $2^{\prime \prime \prime}$ im grössten Durchmesser haltenden, dreieckigen mit hellbraunem „Schleim" überzogenen

*) v. Ammon's Zeitsclir. III. p. 103. 
Glassplitter. Reactionslose Heilung. Sehschärfe Kauru geschwächt.

28. Hirschberg*): Dr. phil., 26 Jahre, aufgenommen 17. Oetober 1873, hatte sich als 15jähriger Junge durea eine Explosion einer Glasflasehe das Gesicht und Auge verletzt. Sehkraft nach der Behandlung gering, auch später durch eine Operation nicht mehr gebessert. Wiederholte Entzündungen gingen auf Ruhe und Dankelzimmer zurück. In den Anfällen namentlich starise Lichtscheu; das gesunde Auge nie betheiligt. L. A. myopiseh, aber sonst normal. R. A. schielt nach aussen um 2-3 Linien; Finger nur in nächster Nähe; Blepharospasmus und grosse Unruhe des Auges. Tension herabgesetzt, auf Druck empfindliche Ciliargegend. Rings am die Hornhaut besteht eine tief geröthete Injectionszone wie bei alter Iritis oder Cyelitis. Die Hornhaut enthält zwischen dem horizontalen Durchmesser und dem ,unteren

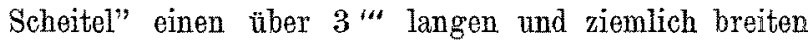
Narbenzug oder vielmehr eine Succession von 3 einzelnen, aber dicht aneinander stossenden alten Perforationsnarben, die einen gelblich weissen Farbenton besitzen, mit der Iris verwachsen sind und an denen die am meisten nach innen zu gelegene eine dreistrahlige Figur wie von einem Blutegelstich herrührend darstellt. Im oberen inneren Quadranten der Hornhant, $1-\mathbf{1}^{1 / 2}$ " von ihrem Rande entfernt, zieht eine zweite, gleichfalls adhaerirende Narbe, die offenbar von einer Iridectomia cornealis herrubrt. Excentrisch nach innen oben wird der artificielle Pupillarraum sichtbar, der aber ebenso wie der natürliche von einer sehnig weissen Schwarte verlegt wird und nur zwei kleine dunklere, d. h. nicht durchscheinende Löcher, darbietet.

Zwischen dieser Schwarte und dem äusseren oberez Pupillarrand sieht man noch hintere Verwachsungen. Unterhalb des lateralen Endes vom Horizontaldurchmesser der Hornhaut, also hinter der am meisten nach aussen gelegenen von den drei Verletzungsnarben erkennt man bei intensiver Focalbeleuchtung einen kleinen glitzernden Körper; derselbe erreicht nach vorn die hintere Hornhaut-

*) Berlin. klin. Wochenschr. 1874, No. 5. 
fläche und ist andererseits in einen bandförmigen Bindegewebszug eingebettet, welcher von ihm nach der Pupillarschwarte hinzieht. Bei starker Senkung des Bulbus eine viereckige glănzend weisse Narbe in der vorderen Linsenkapsel und dicht dahinter eine umschriebene kleine Trübung der Corticalis.

Extration - Länge des Splitters $6 \mathrm{~mm}$, Breite $2 \frac{1}{2}$,

Dicke $2 \mathrm{~mm}$. Form: unregelmässig vierkantige Pyramide. Gewicht: 4 ctgr. Heilung in 10 Tagen; Finger in 3 Fuss.

Auch bei diesen Fremdkörpern kommt, wie man sieht, die mechanische Wirkung zur Geltung; die durch die Bewegungen der Iris hervorgerufenen Insulte führen $\mathrm{zu}$ Schmerzen und wiederkehrenden Reizzuständen, deren transitorischer Charakter von dem Vorhandensein oder Fehlen mechanischer Reizung abhängt.

Der Glassplitter kann frei bleiben oder er wird durch organisirtes Exsudat auf der Unterlage fixirt. Die Bedingungen, von welchen letzterer Vorgang abhängt, sind aus den Beobachtungen nicht mit Bestimmtheit zu entnehmen; es fragt sich, ob die Exsudation von der Verletzung als solcher oder von einer stattgehabten Operation herrührte, oder ob sie der Wirkung des Fremdkörpers zuzusehreiben ist. Wie mir Herr Prof. Leber mittheilt, hat er beobachtet, wie ein Glassplitter von $6 \mathrm{~mm}$ Länge, welcher aseptisch in die vordere Kammer eines Kaninchens eingeführt war und anfangs vollkommen frei beweglich lange Zeit dem unteren Theil der Iris auflag, nach Verlauf von 3 Monaten allmälig durch eine zarte Bindegewebsneubildung eingekapselt wurde. Es trat dabei mit geringer Injection eine Trübung des entsprechenden unteren Theiles der Hornhaut ein, die sehr langsam zunahm. 14 Monate nach der Operation wurde das Auge anatomisch untersucht, wobei sich der Glassplitter durch zartes Bindegewebe auf der Vorderfläche der Iris befestigt fand.

Es kann hiernach nicht bezweifelt werden, dass es bei Glassplittern zu einer Art von Einkapselung kommen 
kann, welche von der dauernden Wirkung des Fremokörpers abhängt, womit auch die Beobachtung in den: Jäger'schen Falle ganz gut übereinstimm'. Was die $\mathrm{is}$ klärung dafür angeht, so sind wir nicht der Ansicht, dass blosse mechanische Reizung entzündliche Exsudation und Bindegewebsneubildung nach sich ziehen könne, doch kommen hier Wirkungen verschiedener Art, die zum Theil anch als chemische anzusehen sind, in Betracht. Win scharfer Splitter, der in der vorderen Kammer frei beweglich ist, kann die Iris and hintere Hornhautwand $z a$ oft wiederholten MaIen verletzen, das Endothel der vorderen Kammer abschürfen und dadurch zu Quellungstrübung der Hornhaut führen, welche vielleicht als solche zu leichter Bindegewebsentwicklung Anlass giebt. Uebrigens ist bei sehr langem Verweilen auch die Möglichkeit einer direkten chemischen Wirkung nicht ganz ausser Acht zu lassen, da das Glas in alkalischen Flüssigkeiten nicht vollkommen unlöslich ist.

Ist ein chemisch vollig indifferenter Körper aseptisch in das Auge hineingelangt, so ist zu erwarten, dass er auch bei noch so langem Verweilen im Auge niemals eitrige Entzündung hervorrufen wird. Dagegen ist es sehr wohl möglich, dass er Jahre lang unschädlich bleibt und dann erst durch irgend eine Veranlassung die Ursache von einfachen Reizzuständen der obenerwähnten Art abgiebt, die aber als solche nicht mit entzündlischer Exsudation einhergehen. Solche Reizzustände können auch sympathische Reizung des anderen Auges herbeiführen, aber nicht wahre sympathische Entzündung, zu deren Zustandekommen höchst wahrscheinlich die direkte Fortleitung eines entzündlichen Prozesses von einer Seite zur anderen erforderlich ist. Die spärlichen bekannt gewordenen Beobachtungen, welche mit diesen Ansichten nicht zu harmoniren scheinen, stehen damit uur scheinbar im Widerspruch, oder sie lassen sehr wohl eine andere Deutung zu. Zunächst steht 
damit ganz im Einklang die Erfahrung, dass ein Auge, welches viele Jahre lang ohne Beschwerde einen Fremdkörper in der vorderen Kammer beherbergte, in Folge einer Contusion von schmerzhafter Reizung ohne Exsudation befallen wird:

29. Ivert*): 40jähriger Mann; Verlust des Sehvermögens vor 17 Jahren durch eine Explosion; das Auge seitdem völlig reizlos. Seit 14 Tagen in Folge oines Schlages anf das Auge Rothung und Schmerzen an demselben. Adhärente Narbe am Hornhautrand mit Verziehung der Pupille; traumatische Cataract. Im unteren Theil der vorderen Kammer ein Stecknadelknopf grosser Fremdkörper, offenbar ein kleines Steinfragment, durch zartes Gewebe an seiner Stelle fixirt. Keine Spur von friseher Verletzung der Hornhaut. Starke pericorneale Injection, lebhafte Ciliarneurose. Weiterer Verlauf unbekannt.

Ob hier der Fremdkörper bei der Entstehung der Reizerscheinungen überhaupt betheiligt war, ist noch fraglich, da an einem Auge mit adhaerenter Hornhautnarbe eine heftige Contusion gleiche Folgen haben kann auch ohne Fremdkörper. Aber selbst die Mitwirkung des letzteren zugegeben, ist doch bemerkenswerth, dass nach 14tägiger Dauer der Reizerscheinungen Nichts von entzündlicher Exsudation, weder an Hornhaut noch Iris, bemerkt ist.

Wenn in folgendem Falle erst nach 19jährigem Verweilen eines Steinsplitters eitrige Iritis auftrat, so kann diese sicherlich nicht dem Fremdkörper zugeschrieben werden, um so weniger, als nach einem vergeblichen Extractionsversuch und einer Iridectomie, trotzdem der Fremdkörper im Auge blieb, die Iritis zurückging. Eine sonstige Ursache kann ja sehr wohl mitgewirkt haben, worüber natürlich keine bestimmte Vermuthung aufzustellen ist.

*) Traité prat. et clin des bless, du globe de loeil. Paris 1880, p. 89 . 
30. Friedinge $\mathrm{r}^{*}$ ): Findringen eines Steinsplitters in das linke Auge. Zeitweilig treten Entzündungen auf. Nach 19 Jahren heftige Iritis mit Bildung eines kleinen Abscesses. Nach Aussage des Patienten liegt das Steinstück gewöbnlich auf dem Boden der vorderen Kammer. Ein Extractionsversuch gelang nieht, da das Stück beim Versuch, es zu fassen, entschlüpfte; es wurde eine Iridectomie nach unten gemacht. Die Iritis heilte rollständig. Später wurde der winzig kleine Splitter am Grunde der Kammer an der vorderen Linsenkapsel nachgewiesen. Sehvermögen nahezu normal.

So vermissen wir auch in einem von Saemisch**) mitgetheilten Falle, wo ein Basaltstückchen 12 Jahre reizlos in der vorderen Kammer verweilt hatte, den Beweis, dass die dann auftretende Iritis durch den Fromdkörper entstanden war und nicht durch eine andere unermittelt gebliebene Ursache:

31. 31jähriger Mann; vor 12 Jahren Verletzung durch einen Steinsplitter mit geringfügiger Entzündung, aber Erblindung durch traumatische Cataract. Seit 3 Wochen Röthung des Auges und Schmerzen. Winklige Hornhautnarbe, daneben eine zweite kleinere; dreiseitiges Basaltstückchen im unteren Theil der vorderen Kammer mit der getrübten Linsenkapsel zusammenhängend. Frische Iritis mit Kammerwassertrübung, aber ohne hintere Synechie. Nach Extraction des Fremdkörpers mit grosser Iridectomie rasche Heilung der Iritis. Der günstige Ausgang muss hier weit eher der Iridectomie als der Beseitigung des wohl inoffensiven Fremdkörpers zugeschrieben werden.

Ebensowenig liegt in dem folgenden Falle von Sigismund $* * *$ ) ein Beweis vor für die erst nach vielen Jahren eingetretene schädliche Wirkung des Fremdkörpers:

*) Wiener med. Wochenschr. XXVIII. 1878.

**) Zehender's klin. Monatsbl. III. p. 46. 1865.

***) Berlin. klin. Wochenschr. 2. Febr. 1880. No. 5. 
32. 59 jähriger Mann. Erblindung vor 47 Jahren durch Stoss an einen Ast; erst im letzten Jahre Schmerz und Entzündung. Cornea in der unteren Hälfte zum Theil oberflächlich getrübt, in der Trübung eine hirsekorngrosse Narbe. Pupille mittelweit, auf Atropin nicht reagirend, in ihr ein gelblicher Fremdkörper, der sich nachher als ein $5 \mathrm{~mm}$ langes, $2 \mathrm{~mm}$ breites, dünnes, dreieckiges Holzsplitterchen erwies. Vollständige Cataract. Bulbus etwas „verhärtet", starke Injection, Druckempfindlichkeit etc. Modifieirte Linearextraction mit Entfernung des Fremdkörpers. Die Empfindlichkeit des Auges verlor sich; Patient konnte aber nur hell und dunkel unterscheiden; der Glaskörper sehien getrübt.

Es macht am meisten den Eindruck, als ob es sich um einen chronischen glaucomatösen Zustand gehandelt habe, dessen directe Beziehung zum Fremdkörper mindestens nicht erwiesen ist.

Was endlich die Fälle angeht, in welchen erst längere Zeit nach einer Verletzung ein bis dahin völlig reizlos vertragener Fremakörper sympathische Störungen des anderen Auges hervorruft, so ist uns kein einziger Fall bekannt geworden, in welchem diese Folgen zweifellos als sympathische Entzündung zu betrachten wären. Die genauere Prüfung der an sich sehr spärlichen Fälle, welche als Beleg für das Gegentheil angeführt werden könnten, lässt dieselben für uns nicht als beweiskräftig erscheinen, indem man bisher einfache sympathische Reizung nicht genügend von ächter sympathischer Entzündung unterschieden hat. Als Beispiel führen wir folgende Beobachtung von Taylor*) an:

33. 14jähriger Knabe klagt übor Sehstörung (dimness of vision) und Liehtschen an beiden Augen, mit Schmerz und Thränen, vorzugsweise am rechten. Bei der Untersuchung fand sich das linke Auge matt und angegriffen

*) Ch. B. Taylor: Two cases of foreign bodies long retained in the anterior chamber of the eyeball etc. - Med. Times and Gaz. 1870, p. 284 (case 1).

v. Graefe's Archiv für Ophthalmologie, Xxvmr. 2. 
(duil and oppressed) mit träger Pupille, offenbar durch sympathische Affection (from sympathy). In der vorderen Kammer des rechten Auges fand sich auf dem unteren Theil der Iris ein hellrothes Körperchen. Drei Jahre zuvor war das Auge durch einen abgesprungenen Splitter verletzt worden, hatte sich aber nach dreiwochentlicher Behandlung vollständig erholt und in der Zwischenzeit keinerlei Beschwerden gemacht. Durch eine Incision im unteren Theil der Cornea wurde ein Stïckchen Ziegelstein im Gewichte von 1 Gran entfernt. Dor Patient musste darauf 3 Wochen mit Blutegeln und Mercurialien behandelt werden, wurde aber mit vollkommenem Sehvermögen an beiden Augen hergestellt, das sich auch später erhielt.

Wie man sieht, genügt die Schilderung des Befundes an dem sympathisch afficirten Auge nicht, um eine Iritis zu diagnosticiren; auch der Ausgang in vollständige und dauernde Heilung lässt vermuthen, dass es sich nur um einen sympathischen Reizzustand gehandelt habe.

\section{B.}

Chemisch indifferente Fremdkörper im Corpus vitreum oder in den dasselbe umschliessenden Angenhäuten.

Wir finden im Ganzen 6 Falle, die in diese Categorie zu rechnen sind, und welche unsere Ansicht vollkommen bestätigen, dass aseptisch eingedrungene Fremdkörper, die zugleich chemisch indifferent sind, dauernd im Auge vertragen werden, ohne irgend welche Entzündung hervorzurufen. Die Mehrzahl betrifft merkwurdiger Weise ins Auge eingedrungene Schrotkörner (4 Fälle), theils frei im Corpus vitreum suspendirt, theils den Wandungen desselben aufgelagert; es steht dies in Einklang mit der Annahme, welche sich aus den am vorderen Abschnitt des Auges gemachten Erfahrungen ergeben hat, dass das Blei als chemisch indifferent für die Gewebe des Körpers zu betrachten sei. Uebrigens liegen über dieses Metall bisher 
noch keine Ergebnisse von Thierversuchen vor. Besonders merkwürdig ist der Fall von Schneider, in welehem die gleichzeitige Anwesenheit von 4 durch Zersplittern eines Geschosses entstandenen Bleipartikelchen in der Tiefe des Auges angenommen werden musste, und der nur kurz erwähnte von Sichel und Gayat, wo das Auge ebenfalls 4 Bleipartikelchen beherbergte. Von den beiden anderen betrifft der eine, nur summarisch mitgetheilte, ein Pulverkorn; in dem Falle von Jacobson endlich soll es sich um einen Steinsplitter gehandelt haben; wir halten es aber nicht für uberflüssig zu bemerken, dass die Natur des Fremdkörpers uns in diesem Falle nicht ganz sicher zu stehen scheint und dass es sich den gemachten Angaben nach auch um einen Stahlsplitter gehandelt haben könnte. Uebrigens ist dies deshalb von geringerer Wichtigkeit, weil die Beobachtung nicht lange genug fortgesetzt wurde, um darzuthun, ob das Auge dauernd von etwaigen Folgen der Anwesenheit des Fremdkorpers versehont blieb, wie man solches ron einer chemisch nicht indifferenten Substanz erwarten könnte.

34. L. v. Wecker*) untersuchte einen Hann, bei dem ein Schrotkorn von intensiv graublauem Metallglanze im Glaskörper anfgehängt war in der Weise, wie die Kinderbälle in einem Schwungnetz. Dieses glänzende Metallkorn befand sich seit Jahren im Ange eingekapselt.

35. A. v. Graefe**): Schrotkorn im linken Auge. Am inneren Cornealrand kleiner Irisprolaps. Anstritt von wenig Corpus vitreum. Patient sah nichts, nur eine milchweisse Fläche, in der Mitte mit einem Blutstreifen. Sondirung ohne Resultat. Leicht ableitende Behandlung im Dunkelzimmer; sechs Tage später konnte Patient wieder Objecte sehen und war die Sehschärfe seit geraumer Zeit stationär geblieben.

*) Die Erkrankungen des Uvealtractus und des Glaskörpers. Handbuch der gesammten Angenheilkunde. Bd. IV. p. 705.

**) Arch. f. Ophth. III. 2. p. 341. 
Sechs Monate nach der Verletzung: unvollkommen übernarbter Irisvorfall an der inneren Scleracornealgrenze; Pupille erweitert und nach dem Vorfall hin verzogen. Functionelle Prüfung: mittlere Schrift leidlich fliessend; feinere mühsam lesbar; eigenthümlich defectes Gesichtsfeld. Ophthalmoskopisch: Erhebliche und sehr verbreitete Glaskörpertrübungen, unbestimmt verwischte Theile der entfärbten Chorioidea. Von der Gegend des inneren Aequators begann ein vom Augenhintergrund mehrere Linien in das Corpus vitreum nahezu horizontal verlaufender Fortsatz, welcher mitten im Glaskörperraume mit einem freien Rande aufhörte. Der Fortsatz ist diaphan und wird nach der Peripherie zn zarter; im Fortsatz liegt das Schrotkorn, welches in einer Kapsel von Membranen unter dem horizontalen Durchmesser gehalten wurde. Linse klar. Im hinteren Glaskörperraum flottiren membranöse. Fetzen, die mit ChoIestearin besäet sind.

36. Schneider*): Einem 25jährigen Manne waren vor 2 Jahren Stücke einer an Eisen anschlagenden Bleikugel ins linke Auge geflogen; starke Blutung, längere Zeit heftige Schmerzen, Amaurose. Das Sehvermögen kehrte nach und nach zu dem jetzt vorhandenen Grade zurück.

Rechtes Ange normal; linkes Auge H 1/4, $\mathrm{S}=\frac{20}{50}$, Gesichtsfeld nach oben aussen beschränkt. Im Bereich des äusseren unteren Hornhautquadranten findet sich im Scleralbord eine leicht pigmentirte $3 \mathrm{~mm}$ lange, $1 \mathrm{~mm}$ breite narbige stelle. Cornea ganz normal, ebenso Iris bis auf eine der Narbenstelle gegenüber liegende Partie. Hier ist dieselbe entfärbt und mit der erwähnten Narbe in der Art verwachsen, dass der Pupillarrand des betr. Iristheiles frei bleibt, derselbe aber hakenformig nach dem Ciliarkörper nmgebogen ist. Von dieser Irispartie gehen einige feine Fäden zu einer Membran, die das ganze Pupillargebiet ausfüllt, im Centrum etwas dichter wird und hier eine lineare von oben aussen nach unten innen gestellte undurchsichtige Trübung besitzt (offenbar vordere Kapsel nach Resorption der Linse Ref.) Die

*) Zehenders Mionatsblätter XV. 1877. p. 292. 
ganze Membran ist mit zahlreichen, stecknadelknopfgrossen Plättchen, die bei seitlicher Beleuchtung einen intensiven metallischen Reflex geben, besetzt. Bei Bewegungen des Auges aus der Tiefe desselben momentanes starkes Glänzen, welches wieder schnell nach unten verschwindet. Die Untersuchung mit durchfallendem Licht zeigt, dass der Glanz von einem pyramidenartigen Körper herrührt, der besonders deutlich ist, wenn Pat. das Auge nach unten innen richtet. Die Lage entspricht constant der Mitte des untern innern Corneaquadranten, und zwar in der Weise, dass der breitere Theil - Durchmesser $3 \mathrm{~mm}$ - nach vorn unten, die Spitze - $1 / 2 \mathrm{~mm}$ Durchmesser - nach innen oben steht. An der Basis befindet sich noch ein Anhang von ca. $1 \mathrm{~mm}$ Breite. Bei geringen Excursionen des Auges macht der Körper Bewegungen wie etwa ein angeketteter Nachen; die Spitze zeigt immer die geringste Verschiebung. Durch rasche Bewegungen des Anges von unten nach oben wird neben dem froi im Glaskörper sehwebenden noch ein zweiter Körper bis zur Hälfte des Pupillarfeldes in die Höhe geschlendert; dieser ist fon grösseren Dimensionen, rund, obne den hellen Glanz, sinkt viel schneller nach unten und vorn und verschwindet an der inneren Seite des verticalen Meridians. Lage und Form konnte nicht genaner eruirt werden.

Ophthalmoskopisch zeigt der Grund des Auges Folgendes: Verfolgt man vom Opticuseintritt ausgehend den Lauf eines nasal kommenden starken venösen Gefässes, so kommt man zu einer vor dem Aequator liegenden sehnig glänzenden Stelle, wo das retinale Gefäss wie abgebrochen verschwindet; umgebende Retina unverändert, Chorioidea stark pigmentirt; das Pigment setzt sich in einem linearen Streifen von 2-3 mm nach dern Aequator $\mathrm{zu}$ fort. Die erwähnte Veränderung in den Bulbushänten zeigt eine länglich runde Form im grössten Durchmesser von ea. $4 \mathrm{~mm}$. Von der Mitte der erwähnten Stelle nach oben einen Papillendurchmesser, entfernt von jenem sieht man eine zweite aequatorial gestellte dicke Pigmentanhäufung von $5 \mathrm{~mm}$ Breite und $2 \mathrm{~mm}$ Länge, die von einer lichten Zone atrophischer Chorioidea umgeben ist. Retina auch hier unverändert. 
Vom Opticus nach innen unten ea. 2 Papillendurchmesser von jenem entfernt, sieht man wieder einen glänzenden Körper von $1 \mathrm{~mm}$ Durchmesser und ron diesem noch etwas mehr nach innen einen zweiten ron doppelter Grösse; beide, in die Retina eingebettet, zeigen weder diese noch die Chorioidea am Sitze wie in der Umgebung dieser Körper irgendwelche ophthalmoskopiseh wahrnehmbare Veränderung. Da eine solche auch nicht in der Sclera oder Cornea sichtbar ist, so muss die im Scleralbord befindliche Narbenstelle als der einzige Eintrittspunkt von sämmtlichen in Bulbus befindlichen Metallfragmenten angesehen werden. Von den 4 Metallstücken erreichten alle die gegenüberliegende Bulbuswand, jedoch in versehiedener Richtung; während die zwei in der Retina sitzenden an diese in einer mehr wagerechten Linie gelangten und dort ohne zu ricochettiren sitzen blieben, so erreichten die zwei grösseren dem Eintrittscanal direct nach oben entgegengesetzte Punkte. Der eine trennte Retina und Chorioidea, prallte zurück und kam auf den Boden des Bulbus zu liegen, wo er frei beweglich blieb, während der andere, obne die Retina zu trennen, dio Chorioidea verletzte, dann ebenfalls zurückflog und im Glaskörper fixirt wurde. Letzteres muss unbedingt aus der Lage wie aus der Art der Bewegung geschlossen werden, wenn auch dieses ophthalmoskopisch nicht zu erkennen ist. Das absolute Fehlen der Veränderung in der Retina beweist, dass sich die Netzhaut gegen in sie eingebettete Fremdkőrper ebenso indifferent verhalten kann, wie dies vom Glaskörper bereits bekannt und durch vorliegenden Fall auf das Prägnanteste wieder gezeigt wird.

37. Sichel und Gayat*): In einem Fall konnte man an einem durch Verletzung erblindeten Auge genau den Augengrund sehen und die Gegenwart von 4 Bleikörnern, welche von einer graulichen Membran umhüllt und an der vorderen Partie der Sclera durch weissliche Fäden befestigt waren, constatiren.

38. Bergeret ${ }^{* * *}$ ) sah ein Pulverkon nahe neben der Papille

*) Ivert, Traité ete. p. 651.

*) I vert, Traité etc. p, 694 . 
sitzen, welches durch Cornea, Iris, Linse und Glaskörper gedrungen war, sich nahe der Papille festgesetzt hatte, ohne die geringste Störung herbeizuführen.

39. Jacobson*): Beim Schleifen eines Mühlsteins war ein abgesprungener Fremdkörper, wie man annahm, ein Steinfragment, ins Innere des Auges bis in die Nalle der Papilla optica durcbgedrungen. Vier Wochen, nachdem Linearextraction mit Iridectomie versucht worden war, die aber wegen Glaskörperverfall unterbrochen werden musste, hatte Patient mit $+5 \mathrm{~S}=\frac{1}{8}$ and einen circumseripten Gesichtsfelddefect, der der Retinalwunde fast genau entspricht. Cornea, Pupille bis auf die Operationsnarben normal, vordere Kammer tief. Durchscheinende membranöse Cataracta secundaria, in deren Mitte eine vollkommen klare Pupille, Glaskörper ungetrübt; etwas nach oben innen von der Papilla optica eine glänzend weisse querovale Plaque blosliegender Sclera, zwischen deren Fasern ein kleiner dunkler Fremdkörper mit dem hinteren Ende eingedrungen, während das vordere kurz vor der Innenfläche der Sclera steckte. Chorioidea. über der weissen Stelle zerrissen mit breiten klaffenden Rändern.

Wie schon oben bemerkt wurde, muss hier auch an die Möglichkeit gedacht werden, dass der fremde Körper ein Stahlsplitter war, der beim Mühlsteinschärfen ebensowohl ins Auge fliegen konnte, mit welcher Annahme auch die dunkle Farbe in Einklang stehen würde. ob das Auge dauernd von schädlichen Folgen der Anwesenheit des Fremdkörpers verschont blieb, ist ungewiss, da die Beobachtung, soweit darüber eine Mittheilung vorliegt, sich nur auf einen Monat erstreckte.

Fälle von chemisch indifferenten Fremdkörpern, welche kurz nach der Verletzung keine Entzündung hervorgerufen hatten und in welchen solche erst längere Zeit nachher auftrat, sind uns in der Literatur nicht vorgekommen, was wir als eine nicht unwichtige Bestätigung unserer oben erörterten Anschauungen za betrachten berechtigt sind.

*) Arch. f. Ophth. XI. 1. p. 129. 
II.

Chemisch nicht indifferente metallisehe Fremdkorper.

Von chemisch nicht indifferenten Fremdkörpern stehen uns nur Beobachtungen über Eisen-, Stahl- und Kupferstückchen zu Gebote, welche überhaupt die bei weitem grösste Mehrzahl der Fälle aseptisch ins Auge gedrungener" Fremdkörper ausmachen.

Die Fremdkörper aus Blei haben wir oben, auf klinische Beobachtungen gestützt, den chemisch indifferenten Substanzen anreihen zu müssen geglaubt, doch sind darüber noch directe Versuche erwünscht. Bei dem Eisen kann an einer chemischen Wirkung nicht gezweifelt werden; dieselbe ist an dem Auftreten rostbrauner Färbung, entfernt von dem Fremdkörper, z. B. in der Linse, sicher zu erkennen; auch für das Kupfer ist eine chemische Wirkung aus unten anzuführenden Gründen wahrscheinlich. Wir stellen zunächst die Beobachtungen nach der Natur des Fremdkörpers, Eisen oder Kupfer, und nach dem Sitz desselben im vorderen oder hinteren Bulbusabschnitt zusammen, um so die möglichen Folgen ibres Aufenthaltes im Auge weiter zu untersuchen.

\section{A.}

Fremdkörper aus Eisen, Stahl oder Kupfer in der vorderen Augenkammer und deren Umgebungen.

a) Eisen oder Stahl.

40. Stellwag*): Ein Nachtwächter, dem gegen Mittag ein Eisenplättchen von 10" Grösse und 1/4 “' Dicke in die vordere Kammer eingedrungen war, konnte sich am Abend nicht zur Extraction entschliessen, weil trotz eines starken Marsches nicht die geringste Gefäss-

*) Stellwag, Die Ophthalmologie vom naturwissenschaftl. Standpunkt. Freiburg i. Br. 1853. Bd. T. p. 733 (Note 66). 
injection vorhanden war und er keine Sehstörung oder Schmerz gespürt hatte.

41. Fischer*) sah ein mehrere Linien langes Stück Metallsaite 14 Tage lang in Cornea und Iris stecken ohne Spur von Entzündung; das vordere Ende ragte ein wenig über die Hornhautoberfläche hervor, so dass es mit einer Pincette gefasst und heransgezogen werden konnte.

42. Taylor**): Ein Eisensplitter hatte die Hornhant durehdrungen und, mit dem einen Ende in ihr haftend, mit dem anderen die Iris berührend, einen Monat in der vorderen Kammer gelegen.

43. Schiess-Gemusens $* * *$ ): Einem 24jährigen Mann flog beim Hacken auf dem Acker etwas ins rechte Auge. Nach 14 Tagen constatirte man mässige Lichtscheu, starke Secretion und Injection des Bulbus, eine strichförmige Narbe in der sonst klaren Cornea; Iris entfärbt. Pupille eng. Auf dem oberen inneren Pupillarrand, diesen etwas überragend, ein kleiner länglicher Fremdkörper und nebenan noch ein kleines metallglänzendes Partikelchen. S nach Atropin $=\frac{20}{40}$. Pupille erweitert sich nur mangelhaft. Besserung dureh Eis und Atropin. Pupille wird weiter mit Ausnahme an der Fremdkörperstelle. Erst 4 Tage nach Anfang der Beobachtung wurde eine feine strahlige linsentrübung der hinteren Corticalis beobachtet, die aber nicht weiter schritt. Da das Auge nach weiteren 14 Tagen vollig reizlos war, wurde Patient mit dem Fremdkörper entlassen.

44. Coutes †): L. L. 36 J., klagt am 8. September 1877 über unvollkommenes Sehen des linken Auges. Schmerz and Entzündung. Zwei Monate vorher war ihm, als er auf dem Felde arbeitete, Etwas ins Ange geflogen; ein kleiner

*) Lehrbuch der gesammten Entzümdungen und organischen Krankheiten des menschlichen Auges etc. Prag 1846. S. 18.

**) Med. Times and Gazette 1876. p. 284 (case 2).

**) Correspondenzblatt f. Schweizer Aerzte. X. Jahrg. No. 21.

$\dagger$ The lancet I. vol. 1878, p. 719. 
Körper, der die Pupille verdeckte wurde gesehen, Iridectomie, Eisenstück - Sehschärfe gut.

45. André*): Ein Stahlsplitter hatte die Hornhaut durchschlagen und fand sich in der vorderen Kammer, in die Iris eingedrungen. Am folgenden Tag trat Entzündung ein mit starker Exsudatbildung in der Umgebung des Fremdkörpers, wodurch dieser ganz verhüllt wurde. Im Laufe der nächsten Tage nahm die Entzündung raseh $a b$, und war nach 6 Tagen ganz verschwunden; das Exsudat zog sich auf die nähere Umgebung des Fremdkörpers zusammen und wurde durchscheinend; später schloss ein halbdurchsichtiges, der vorderen Fläche der Iris anhaftendes und mit der Pupille bewegliches Bläschen das schwärzliche Eisenfragment ein; nach 5 Mionaten bestand. keinerlei Reizung.

Auffallond an dieser Beobachtung ist die Anfangs aufgetretene Entzündung und Exsudatbildung; dieselbe kann wobl nur dadurch erklärt werden, dass zugleich mit der Verwundung eine Infection stattfand, die aber mehr gutartiger Natur war, so dass die dadurch resultirende Entzündung bald wieder rückgängig wurde, während der Fremdkörper selbst, nach dieser Ansicht, keine nennenswerthe Störung hervorrief.

46. Dix on **) zog einen schwarzen Punkt aus der Iris aus, welcher gerade zwischen ihrem Ciliar- und Pupillarrand eingeheilt war und sich als ein in Lympho eingeschlossenes Stahlstückchen erwies, welches vor 18 Monaten eingedrungen war.

47. Hirsch berg **): Im linken Auge eines jungen Schmiedes fand sich gerade am ,unteren Hornhautscheitel" (sic!) eine ganz umschriebene weisse Narbe und dicht dahinter auf der Iris ein viereekiger prominenter Metallsplitter von ca. $5 / 4 \mathrm{~mm}$ Länge und $3 / 4 \mathrm{~mm}$ Breite, ziemlich dick, nicht eingekapselt, aber der Iris fest anhaftend; derselbe zeigte abgesehen von den Randern, die sehwärzlich waren, einen hellen metallischen Glanz. Augengrund und Sehschärfe normal. Patient hatte keine Ahnung

*) Annal, d'oculist T. LXVIII, p. 184 (1872).

*) Zander und Geissler 1. c. p. 179.

**) Berlin. klin. Wochensehr. 1874. No. 5, p. 55 . 
von dem Gast, den sein Auge beherbergte. Absolut keine Reizerscheinungen.

48. Knapp*): Ein Eisenstückchen war vor 3 Jahren einem 5 jährigen. Knaben in's Auge geflogen. Es trat keine Entzündung ein; das Auge in Gestalt und Spannung normal. Linse absorbirt, so dass man durch den oberen seitlichen Theil der Pupille den Augengrund sehen konnte, während im unteren Theil derselben der Fremdkörper im weisslichen Gewebe noch erkennbar, aber sicher abgekapselt war.

49. Bader**): Ein Stahlsplitter steckte im oberen Theil der Iris; 1/2 Jahre zuvor war er in's Auge geflogen und dieses war einen Monat lang entzundet gewesen. Nachdem die Entzündung zurückgegangen, war keine Störung im Sehvermögen bemerkt. Vierzehn Tage bevor Patient in's Spital kam, sah er undeutlich, hatte Symptome von Entzündung, Schmerzen. Cornea normal; Iris mobil mit Ausnahme eines kleinen schwarzen Punktes der sich mitten zwischen Ciliar- und Pupillarrand befand. Operativ wurde ein dreieckiger schwarzer Körper entfernt, der von organisirtem Exsudat umgeben war. Nach 3 Wochen wurde Patient mit ungestörtem Sehvermögen entlassen.

50. Schiess-Gemuseus ***): Patient stellt sich 29. April 1872 vor, nachdem ihm ein Eisensplitter 14 Tage vorher in's rechte Auge gefahren war. Seitdem Nebel vor demselben; kleine Hornhautnarbe; kleiner Fremdkörper auf der Iris. Sehvermögen $=\frac{2}{3}$. Starke pericorneale Injection. Aufnahme abgelehnt.

Im Herbst 1877 frische Entzündung bei einer Militärübung, nach welcher das Auge wieder ganz ruhig wurde. Am 4. Dee. 1877 war der Humor aqueus trübe; Pupille reagirte träge. Augengrund nur undeutlich sichtbar. Seh-

t) Knapp's Arch. VIII. 1879. p. 80.

**) Ophth. Hosp. Rep. I. p. 139.

**) Correspondenzbl. f. Schweizer Aerzte. X. Jahrg. 1880.

1. Nov. No. 21. Fall 5. 
vermögen $=\frac{20}{200}$. Extraction des Corpus alienum, worauf Sehrermögen sich auf $2 / 5$ und später nahezu auf 1 hob.

Folgender Fall, der hier zu rubriciren ist, kam in der Göttinger Klinik am 19. October 1880 zur Beobachtung:

51. Heinrich Westphale, $33 \mathrm{Jahr}$, aus Hannover. Rechtes Auge im Februar 1879 durch einen abgesprungenen Metallsplitter verletzt; allmäliges Eintreten von Sehstörung; am 9. Juli frische Entzündung, die aber nur etwa 14 Tage anhielt.

Auge frei von Injection; weder an der Cornea, noch an der Sclera ist eine Narbe von einem eingedrungenen Fremdlörper zu entdecken. Auf Atropin Pupille regelmässig erweitert, keine Synechieen; Linse getrubt, in der Mitte abgeflacht und im aequatorialon Durchmesser verkleinert, theilweise resorbirt; nach innen unten klarer Sector, wo die Linse noch ungetrübt scheint. In der Peripherie der vorderen Corticalis ein Kranz rostbrauner Flecke, wie man sie bei Eisenpartikeln im Innern des Auges sieht.

R. A. Finger in 8 Fuss, mit $+14 \mathrm{D}$ No. 15 J. (nach Atropin), Se frei. L. A. mit $-3,5 \mathrm{D} \mathrm{S}=\frac{20}{30^{\circ}}$.

Diagnose: traumatische Cataract, Eisensplitter im Auge, zweifelhaft $o b$ in der Linse oder deren Umgebung. Therapie Discision.

Die Linse lässt sich leicht durch einen Kreuzschnitt zersehneiden, es treten Linsenflocken in die vordere Kammer vor. (23. Oktober 1880).

8. November. Heilungsverlauf und Resorption der Cataract ohne Reaction; am Boden der vorderen Fammer noch eine kleine Linsenflocke. Pupille beinahe schwarz; lateralwärts noch getrübte Corticalis. Injection noch nicht vollständig zurückgegangen.

Die Hornhaut zeigte schon bald nach der Operation in ihrem mittleren Abschnitt eine ganz leichte Trübung und Mattigkeit der Oberfläche, welche nach unten innen scharf begrenzt ist, nach oben aussen dagegen sich allmälig verliert. Nahe ihrem unteren Rande sehliesst sie zwei sehr kleine etwas längliche wasserklare Bläschen ein, 
und kann dadurch bestimmt in das Hornhautepithel localisirt werden. Wegen dieser Trübung erhielt man mit dem Spiegel bisher nur schwaches rothes Licht aus dem Augengrund und war von dem Fremdkörper nichts gefunden, nur glanbte man vorgestern eine ganz kleine, leicht bewegliche Trübung hinter der Linse zu sehen. Nachdem sich die Hornhaut mehr gehellt hat, erkennt man hente bei einer bestimmten Beleuchtung ein sehr kleines hellglänzendes Metallplättehen von ca. 1 mm Länge und $1 / 4-1 / 3 \mathrm{~mm}$ Breite, vertical gerichtet, gegenüber der Pupillenmitte in eine zarte Membranflocke eingeschlossen, anscheinend dicht hinter der hinteren Kapsel im Glaskörper; es scheint zuweilen leicht uu schwanken.

13. November 1880. Fortschreitende Resorption der Linsenreste, keine Injection mehr vorhanden, Hornhauttrübung geringer.

Die Hornhautoberfläche ist wieder glatt und spiegelnd, die Bläschen verschwunden; die Trübung zarter, bei Tageslicht kaum mehr sichtbar, ihr unterer Rand ist etwas nach oben zurückgewichen. Bei focaler Beleuchtung erscheint sie als ein quer über die Hornhaut ziehendes Band, dessen unterer Rand etwa der Grenze zwischen unterem nnd mittlerem Drittel der Hornhauthöhe entspricht, und dessen oberes $2-3 \mathrm{~mm}$ vom oberen Hornhautrande entfernt ist. Der Streifen verschmälert sich beiderseits, besonders lateralwärts, reicht aber im horizontalen Meridian ziemlich bis zum Rande. An der Stelle der früheren Bläschen zeigt der untere Rand zwei kleine Einbiegungen. Dio Trübung lässt keine deutliche Parallaxe gegen die kleine Stichnarbe der Discision erkennen, was mit der Localisirung im Epithel übereinstimmt.

Einige Linsenflocken aussen unten in der vorderen Kammer. Pupille zu durchleuchten; Augenhintergrund mässig versehleiert; Papille sichtbar.

Das Metallstückehen ist viel deutlicher zu sehen und die Umgebung von Linsensubstanz frei geworden; es liegt dicht hinter der hinteren Kapsel, von minimaler Breite, wie ein feiner metallglänzender Strich, ungefähr senkrecht gerichtet; dahinter im Glaskörper zarte flockige bewegliche Trübungen. Bei erweiterter Papille and 
seitlichem Einblick sieht man hinter dem Rand der Pupille fast ringsum einen Kranz von braunen Flecken, offenbar mit Eisenoxyd imprägnirte Linsenreste.

18. November 1880. Kein Atropin mehr. Hornhauttrübung bis auf einige kleine grauliche Fleckchen, die nur bei focaler Beleuchtung sichtbar sind, verschwunden. Pupille schwarz, leicht birnförmig, nach unten weniger erweitert, von Linsenresten kaum noch etwas zu bemerken. Nach aussen unten ein Sector der Iris, dem eine bräunliche Linsenflocke aufgelagert war, etwas gelblich verfärbt. Angengrund noch immer durch zahlreiche flottirende Glaskörperopacitäten verschleiert; Fremdkörper völlig frei, in oder dicht hinter der hinteren Kapsel. - Entlassung. - R. A. mit $+10 \mathrm{D}, \mathrm{s}=\frac{20}{200}$; mit $+15 \mathrm{D} \mathrm{No} .3$.

24. December 1880. Auge reizlos; Pupille vollig schwarz. Befund wie oben. Mit $+10 \mathrm{D}$ nach Atropin $\mathrm{S}=\frac{20}{100-70^{\circ}}$

Der Kranz rostbranner Flecken hat sich entschieden verkleinert, das Eisenplättehen metallisch glänzend in der Mitte der Pupille zu sehen, an einem Kapselrest fixirt, der durchsichtig und nur bei focaler Belenchtung zu erkennen, sich bis zum Rand der Pupille erstreckt. Flottirende Glaskörpertrübungen.

Nach unten, in der Peripherie des Augengrundes eine leicht entfärbte Stelle im Pigmentepithel, darunter etwas dunklere Pigmentirung von nicht normalem Aussehen. - Bei dem so befriedigenden Verhalten des Auges und der Kleinheit des Fremdkörpers wird besehlossen, von einem Extractionsversuch vorläufig abzusehen.

Am 21. October 1882, also mehr als 3 Jahre nach der Verletzung, stellte sich der Patient mit noeh gebessertem Zustande wieder vor; das Auge war indessen völlig frei von Entzündung geblieben und das Sehvermögen hatte noch etwas zugenommen, es betrug $R$. mit $+10 \mathrm{D}$

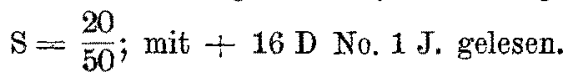

Hornhaut vollständig klar, Pupille rund und beweglich, schwarz, nur in der Thefe nach innen unten der das 
minimale Eisensplitterchen einschliessende Kapselrest. Der Fremdkörper ist noch immer metallisch glänzend; $\mathrm{ob}$ or sich inzwischen verkleinert, bleibt bei seiner an sich so geringen Grösse zweifelhaft.

Einen Fall von Berlin, wo der anfänglich in der vorderen Kammer befindliche Fremdkörper in den Glaskörper versehoben wurde, sowie einen von Samelsohn, wo der Glaskörper wenigstens betheiligt war, werden wir anten bei den Fällen mit tieferem Sitz des Fremakörpers einreihen.
b) Kupfer.

52. Einen Fall, der allerdings wegen der Kürze des zeitlichen Verbleibs des Fremdkörpers im Auge kaum als beweisend betrachtet werden darf, erzählt Galezowsky (Ivert, traité etc. p. 150), der einen jungen Mann operirte, dem ein Stück Zündhütchen vor 24 Stunden durch das obere Lid und die Cornea geschlagen war und hier in in der unteren Partie der Iris ohne die geringste Unbequemlichkeit zu machen sitzen geblieben war.

53. Stbber. *) Einem Corporal war einige Tage vorher ein Kupferhütchenstück in's rechte Auge gesprungen. In der Cornea keine Spur ron einer Wunde, obwohl der fremde Körper ziemlich gross war. Er sass im Centrum der Linse und ragte in die vordere Kammer vor, jedoch ohne den Pupillarrand zu berühren. In seiner Umgebung sah man eine schwache wolkige Trübung. Da der Verletzte gar keinen Schmerz hatte, so verweigerte or die Extraction und trat einige Wochen später wieder in Dienst.

54. Jaeger ${ }^{* * k}$ ) fand ein metallglänzendes $1 \square^{u \prime \prime}$ grosses Zündhütchenstück, welches nur leicht an die Iris angeheftet war; es hatte 5 Jahre lang so in der vorderen Kammer gelegen und abgesehen von der bei der Verletzung aufgetretenen Entzündung die ganze Zeit hindurch keine weiteren Zufälle hervorgernfen, so dass der Patient mit

*) Senge1, Dissert. Strassburg 1859.

**) Staar und Staaroperation. Wien 1854. p. 68. 
diesem Auge so gut sah, wie früher. Durch einen Stoss mit einem Stück Holz an das Auge hatte er sich eine geringfügige Entzủndnng zngezogen, die aber nach wenigen Tagen wieder vollständig zurückging.

Aehnlich sah

55. Tyrrel *) in zwei Fällen Zündhütchenfragmente in der Tris eingewachsen.

56. Dixo ${ }^{* *}$ ) theilt einen Fall mit, wo einem Schuster ein Kupferstück vor 8 Jahren in's Auge gesprungen war. Schmerz und Entzündung. Sehvermögen blieb drei Jahre gut; dann aufeinanderfolgende Entzündungen und Sehverlust. In der Mitte der Irisbreite oben und innen sass ein kileiner Fremdkörper in eine tibröse Capsel eingehüllt. Extraction des $1 \frac{1}{5}$ “ langen Körpers; Resultat: Leucoma corneae, schwache vordere Synechie, Pupille beweglich; Sehvermögen vortrefflich.

57. Hirschber $\mathrm{g}^{* * * *}$ ): $\mathrm{N}$., 18 Jahre alt, stellt sich am 27. Dezember 1879 vor. Patient war vor 9 Jahren ein Zündhütchenstück in's rechte Auge geflogen; or sah darauf einen schwarzen Körper in der Luft schweben. Entzündung trat nicht ein, doch konnte Patient mit dem Auge nicht mehr lesen. Seit Mai wiederholte Anfulle von Entzündung. Zwischen dem unteren Pupillar- und Cillarrand der Iris ein röthlicher, scharf umschriebener, stark herrorragender Knoten wie ein Gumma. Pupille in der unteren Hälfte durch Bindegewebsmembranen versperrt; zahlreiche Synechieen, pericorneale Injection. Durch einen Schnitt am unteren Hornhautrand wurde das Knötchen sammt daran haftender Iris hervorgeholt; es enthielt aber keinen Fremdlörper. Dagegen fand sich auf dem frei gelegten Theil der vorderen Linsenkapsel ein zum Theil messinggelb schimmernder Zïndhütehensplitter, der leicht entfernt wurde. Heilung ohne Störung. Das Sehvermögen blieb durch die vorhandene Trübung der Corticalis bedeutend gestört.

*) Zander u. Geissler. 1. c., p. 179.

**) Annales d'oculistique. T. XXII. p. 17.

***) Knapp's Arch. f. Augenheilkd. IX. 3. p 312. 
Ueberblicken wir die oben mitgetheilten Fälle, so ergiebt sich aus ihnen mit Bestimmtheit, dass auch chemisch nicht als indifferent $\mathrm{zu}$ betrachtende metallische Fremdkörper vertragen werden können, ohne acute eitrige Entzündung hervorzurufen. Ja, bei dem hier zunächst betrachteten Sitz in der vorderen Kammer können auch bei tage- oder wochen- und sogar bei jahrelangem Verweilen Reizerscheinungen vollständig, fehlen, indem sogar jede abnorme Injection vermisst wird, oder wenn sie Anfangs vorhanden war, später wieder verschwindet. Dabei mag dahingestellt bleiben, wie im einzelnen Falle die zuweilen vorhandene Injection oder die sonstigen Reizungssymptome aufzufassen sind; ob als Wirkung des Fremdkörpers selbst oder sonstiger mitwirkender Umstände.

Die Bedingungen, von welchen eine etwaige Einkapselung des Fremdkörpers abhängt, bedürfen noch weiterer Aufklärung; doch steht soviel fest, dass dieselbe auch nach jahrelangem Verweilen ausbleiben kann; wenigstens scheint die Bildung einer dichteren Hülle um den Fremdkörper auszubleiben, wenn sie nicht schon in der ersten Zeit erfolgt ist.

Schon oben wurde eines Falles von Jeaffres on beim Menschen gedacht, in welchem ein Steinsplitter, ohne Entzündung erregt zu haben, nach einigen Tagen durch die Wunde wieder ausgestossen wurde.

Noch merkwürdiger ist die folgende Beobachtung, wonach die Elimination aus der vorderen Kammer bei einem Kupferstückchen mehr als 8 Wochen nach der Verletzung erfolgte, was an einen weiter unten noch zu erwähnenden Thierversuch von Prof. Leber erinnert, wo ein ähnlicher Vorgang an einer in die vordere Kammer eingeführten Nähnadelspitze beim Kaninchen nach ca. $1 \frac{1}{2}$ Jahren beobachtet wurde. Zander und v. Graefe's Archiv für Ophthalmologie, XXVIrt. 2. 
Geissler*) reproduciren aus der medicin. Zeitsehr. vom Verein f. Heilkunde in Preussen 1855 No. 4 folgenden Krankheitsfall:

58. Ein Zündhütchen war durch Cornea und Iris ausserhalb der Pupille in's Auge geflogen; Kammerwasser floss nicht $a b$, eine wirkliche Oeffnung war nicht sichtbar. Acht Wochen vergingen, ohne dass Patient, ausser flüehtigen Stichen etwas klagte, Sehrermögen nieht auf= fallend getrübt. Soleralbindehaut entzündlich aufgelockert. Allmälig erhob sich ein dunkler Punkt in der Iriswunde und bald darauf erschien die spitze des eingedrungenen Zündhütchens in derselben und anch bald in der Hornhautwunde, mit welcher die Iris verlothet war. Der Fremdkörper trat immer mehr nach vorn und fiel endlich bei künstlich erregter Bewegung der Iris ans dieser heraus. 8 Tage später war das Auge von Entzündung frei. Die Linse war ungetrïbt, aber das Sehvermögen blieb etwas geschwächt.

Auch sehr kleine metallische Fremdkörper erhalten sich Jahre lang als solche in der vorderen Kammer; wir haben daher allen Grund, gewisse Angaben zu bezweifeln, nach welchen Eisenpartikelchen sehr rasch durch Resorption aus derselben verschwunden sein sollen. So berichten Zander und Geissler**), dass nach Lawrence und Wardrop abgebrochene Spitzen von Staarnadeln und Staarmessern sich in den ersten Tagen an der Oberfläche schwärzlich färbten und allmälig verschwanden, und dass später auch Cooper und Walton ähnliche günstige Ausgânge gesehen haben. In ähnlicher Weise soll Cline mittheilen, dass die abgebrochene Spitze einer Staaruadel in der vorderen Kammer bereits am nächsten Tage sich oxydirte und nach weiteren 10 Tagen verschwunden war. Hält man die anderen Beobachtungen dagegen, so fehlt es an einem zureichenden Grunde für eine so rasche Auf-

*) I. e. S. 184.

***) 1. c. p. 169 . 
lösung. Ich erinnere z. B. an die schon oben erwähnte Beobachtung, dass Prof. Leber eine Nähnadelspitze bei einem Kaninchen nach fast 1/2jährigem Aufenthalt in der vorderen Kammer in der Einstichsofffnung wieder zum Vorschein kommen sah, nur mit einer Oxydschicht umgeben, so dass sie mit der Pincette gefasst und extrahirt werden konnte, wobei das Auge sich ganz wohl erhalten hatte. Gewiss liegt die Erklärung für obige Beobachtungen sehr nahe, dass die vermissten Metalltheilchen nicht durch Resorption verschwunden waren, sondern sich nur gesenkt and vermöge ihrer Spitze in den unteren Kammerwinkel eingespiesst hatten, so dass sie sich dem Blick entzogen. Hiermit steht auch im Einklang, dass diese Beobachtung eben nur an spitzen Stahlstückchen gemacht ist und z. B. nicht an Kupfer oder anderen Metallen, wobei die Form der Splitter einen solehen Hergang nicht in derselben Weise begünstigt. Eisensplitter pflegen in der vorderen Kammer allmälig ihren Glanz zu verlieren und sich bald mehr bald minder mit einer Oxydschicht zu überziehen. Der Hergang scheint dabei der zu sein, dass die in den Angenflüssigkeiten enthaltene Kohlensäure zunächst kleine Mengen des Metalles als Bicarbonat in Lösung bringt und dass letzteres sodann durch den gleichfalls in den Augenflüssigkeiten absorbirten Sauerstoff zu unlöslichem Eisenoxydhydrat oxydirt und niedergeschlagen wird, wie dies von Herrn Prof. Leber in seinem obenerwähnten Vortrag auseinandergesetzt wird. So erklärt sich auch, wie Ausscheidungen feiner Körnchen von Eisenoxydhydrat in der Linse oder entfernter von dem metallischen Fremdkörper im Corpus vitreum gefunden werden, da das als Bicarbonat gelöste Eisenoxydul sich durch Diffussion in den Augenflüssigkeiten verbreitet, ehe es als unlösliches Oxydhydrat niedergeschlagen wird.

Dagegen pflegen Kupferstuckehen ibren hellen metallischen Glanz zu behalten, wofern sie nicht durch 
Exsudation umhüllt werden, wie u. A. schon Zander und Geissler*) hervorgehoben haben. Es wäre aber zu weit gegangen, daraus den Schluss zu ziehen, dass dabei gar keine chemische Wirkung des Metalls stattfinden könne. Eine geringe Oxydation scheint dabei doch einzutreten; man sieht dies auch an Kupferstücken, die in künstlichen Humor aqueus gelegt sind, wie mir Prof. Leber mittheilt, ohne dass übrigens die Flüssigkeit mit den gewöhnlichen Reagentien die Anwesenheit von gelöstem Kupfer nachzuweisen gestattet. Fur eine chemische Wirkung im Auge spricht auch, dass bei Thierversuchen nach 2-3monatlichem Verweilen von Kupferstückchen in der Linse und in Glaskörper diese Theile in der Umgebung des Fremdkörpers eine eigenthümliche olivenbraune Färbung angenommen hatten, wie Prof. Leber bei Versuchen an Kaninchen beobachtet hat. Die Menge des gelösten Metalles wird aber auch nach langer Zeit nur ausserst gering sein, so dass keine merkliche Verkleinerung des Stückchens eintritt.

Von besonderer Wichtigkeit ist nun die Frage, ob die hier in Rede stehenden Fremdkörper aus oxydablen Metallen, wenn sie auch keine acute eitrige Entzündung erregen, nicht doch durch längeres Verweilen dem Auge schädlich werden, da von der Beantwortung derselben unser therapeutisches Verhalten wesentlich beeinflusst werden muss.

Wir haben namentlich mit Rücksicht hierauf die vorliegenden Beobachtungen je nach dem Sitz des fremden Körpers, in der vorderen Kammer oder im Glaskörperraum, in zwei Gruppen getheilt, weil Prof. Leber bei seinen Versuchen an Thieren bisher nur bei langerem Aufenthalt derartiger Fremakörper im Glaskörperraum, nicht aber in der vorderen Kammer merklichen Schaden für das Auge

*) 1. . . . 170 . 
beobachtet hat. Wir haben daher die vorliegende Frage bauptsächlich an der II. Gruppe von Beobachtungen mit tieferem Sitz des Fremdkörpers zu entscheiden. Für die vordere Kammer ist die Zahl brauchbarer Beobachtungen von länger dauerndem Aufenthalt eines Fremdkörpers recht klein. Sehr bemerkenswerth ist die Beobachtung von Knapp (46), wo ein Eisenstückchen nach Resorption einer traumatischen Cataract 3 Jahre nach der Verletzung in der Linsenkapsel festsitzend gefunden wurde and wo von weiteren Störungen als der durch den Nachstaar bedingten Trübung des Sehvermögens nicht die Rede ist. Dagegen wurde in einem Falle von Bader (47) nach $1^{1} / 2$ Jahren und von Schiess-Gemuseus (48) nach 5 Jahren Auftreten von entzündlichen Erscheinungen beobachtet, welche durch Extraction des Fremdkörpers beseitigt wurden. In Baders Fall soll das Auge gleich nach der Verletzung einen Monat lang entzïndet gewesen sein, weshalb wir, gemäss unseren bei den chemisch indifferenten Fremdkörpern gemachten Bemerkungen, die spätere Entzündung nicht ohne Weiteres auf den Fremdkorper schieben dürfen; die anfänglich durch die Verletzung resp. durch die dabei stattgehabte Infection entstandene Entzündung konnte später selbstständig recidiviren, ohne dass der Fremakörper dabei mitwirkte, Diese Deutung erscheint uns aber in dem Falle von Schiess-Gemuseus gezwungen und unwahrscheinlich, wo anfangs, 14 Tage nach der Verletzung, nur starke pericorneale Infection bemerkt ist, und wo erst nach 5 Jahren Auftreten von Iritis serosa die Extraction des Corpus alienum veranlasste, durch welche das Sehvermögen ganz wiederhergestellt ward. Ich mache hier auf den Fall Westphale (49) ans der Göttinger Klinik aufmerksam, in welchem ein winziges Eisensplitterchen in der Linsenkapsel zurückblieb, nachdem eine traumatisehe Cataract durch Discision vollständig zur Resorption gebracht war. Es fanden sich ausserdem Glas- 
körpertrübungen, die möglicherweise durch die Annahme zu erklären wären, dass der fremde Körper die Linse ganz durchflogen, auch die hintere Kapsel verletzt habe und in der Kapselwunde stecken geblieben sei. Daneben wurde aber eine Neigung des Auges zu leichter Injection und eine eigenthümliche Trübung and vesiculäre Affection des vorderen Hornhautepithels beobachtet; ob diese mit der Anwesenheit des Fremdkörpers in Beziehung stehen, bleibt dahingestellt, dürfte aber nicht unwahrscheinlich sein.

Ebenso verschieden sind die Erfahrungen, welche vorliegen, über Kupferstüeke in der vorderen Kammer: während z. B. Jaeger in einem Falle nach 5jährigem Verweilen durchaus keine Störung und selbst gutes Sehvermögen beobachtete, berichtet Hirschberg einen anderen, wo sich nach 9 Jahren wiederholte Anfälle von Iritis einstellten, obgleich anfangs auf die Verletzung keine Entzündung gefolgt war. Erst weitere Erfahrungen können hier über die Bedingungen Aufschluss geben, von welchen das Auftreten oder Ausbleiben entzündlicher Vorgänge längere Zeit nach der Verletzung abhängt.

B.

Chemisch nicht indifferente Fremdkörper im Glaskörper oder in dessen Wandungen.

Wir stellen zunächst die einschlägigen Beobachtungen zusammen, um dann einige allgemeine Bemerkungen daruber anzuschliessen.

\section{a) Eisen oder Stahl.}

59. Soelberg-Wells*): Ein sehr hleines Eisenstück drang neben der Linse, ohne Opacität derselben za verursachen, bis in den Glaskorper, wo es sich einkapselte; es war

*) Verhandlungen der ophthalmol. Gesellsch. 1863. Zehender's M.-Bl. I. p. 449 . 
während zweier Jahre sichtbar, ohne die Sehschärfe oder das Gesichtsfeld zu stören.

60. Jaeger*): Ein Metallsplitter drang quer durch Cornea, oberen Theil der Pupille und durch die linse parallel der Augenare ein und hatte sich auf dem Boden des Corpus vitreum gelagert. Drei Tage nachher nur die Hornhaut in der Umgebung der Wunde trube, die vordere Kapsel schwăcher, die hintere stärker getrübt; die Verletzung der Linse kennzeichnete sich nur durch einen schwachen Nebel. Die Entzündung beschränkte sich auf die direct verletzten Partieen; die anderen Theile des Anges blieben intact. Der Verletzte klagte nur über eine leichte neblige Trübung; während sich der fremde Körper incystirte, vergrösserte sich die wolkige Trübung der hinteren Kapsel, dagegen verminderte sich die der vorderen bedeutend und die Linse selbst verschwand vollständig. Das Ange behielt seine Form und Functionstüchtigkeit auch im Verlauf dreier Jahre der Beobachtung.

61. Jaeger**): Ein Stahlsplitter drang quer durch den oberen Theil der Cornea, Iris und Linse in das linke Auge. Acht Tage nachher klagte der Verletate über einen leichten Nebel beim Sehen und über ein Gefühl eines Fremdkörpers im Auge. In der Cormea war keine Verletzung mehr zu sehen; die der Iris stellte sich als ein dreieckiger $1 \mathrm{~mm}$ grosser schwarzer Fleck dar, namentlich gut mit dem Augenspiegel. Wunde der vorderen Kapsel vernarbt, mit einer sehr schwachen Trübung umgeben. Wunde der hinteren Kapsel erschien ebenfalls dreieckig. In der Linse konnte man keine Spur des Durchganges eines Fremalkörpors erblicken. Die Incystirung des Körpers, der in der Richtung der Augenaxe auf der Membrana hyaloidea lag, bedingte nur eine locale Entzündung, welche nur die umgebende Glaskörpermembran trüb erscheinen liess, als sie das Maximum ihrer Intensität erreicht hatte. Der Verletate konnte ein Jahr lang das Auge gut gebrauchen, dann

*) Oesterr. Zeitschr. f. prakt. Heilk. 1859. No. 2; nach Zander u. Geissler S. 206.

\% $1 . c$. 
aber Trübung der hinteren Kapsel und Abschwächung der Sehschärfe.

62. v. Graefe. *) Einem 17 jährigen Sehlosserlehrling sprang ein Stück von der Ambosskante ins linke Auge. Er sah unmittelbar darauf einen sehwarzen Fleck vor dem Auge schweben, der genau die Augenbewegungen begleitete, ohne sich im Gesichtsfeld zu verschieben; 14 Tage nach der Verletzung kam Patient in die Klinik. Status: lineare Wunde von 1“" Länge im oberen Cornealrand; Iris adhärent; Pupille ein wenig dahin verzogen. Linse zeigt umschriebene Opacität. Bei Mydriasis: in der vorderen Kapsel der Augenaxe nahe gelegene Wunde, die mit einer weisslichen Substanz verlöthet ist. Strangförmige Trübung der Linse nach innen und oben rom hinteren $\mathrm{Pol}$; sternförmig verbreitete Trübung der hinteren Corticalis. Kein eigentlicher Canal im Corpus vitreum; jedoch einige Flocken. Im Augenhintergrund, in denselben eingelagert, ein Fremakörper, ein lönglicher horizontal liegender Metallsplitter, so lang wie die Papille und etwa so breit wie die Hälfte des Papillendurchmessers. Reflex bläulich metallisch. Netzhaut existirt bis zum Rande des Fremdkörpers. Grössere Unterbrechung desselben auszuschliessen. Anzunehmen ist, dass Retina und Chorioidea durchsehlagen sind; bräunliche Verfärbung und noch bestehende Ecchymosirung der Chorioidea; keine Netzhautablösung. Sehvermögen gut; mittlere Schrift fliessend, kleinere mühsam lesbar. Keine Gesichtsfeldbeschränkung ausser einem kleinen Defect, der Lage des Splitters entsprechend. Nach etlichen Monaten keine Veränderung der Lage des Fremdkörpers, der Linsentrübung und dex Sehschärfe.

63. v. Graefe**): Verletzung des rechten Auges mit kurz darauf folgender Sehstörung. Drei Tage nach der Verletzung: Pupille unregelmässig erweitert. $\mathrm{S}$ etwas vermindert, so dass Patient mit den geeigneten Convexgläsern (wegen traumatischer Accommodationsparalyse) nur mittlere Druckschrift erkennen konnte. Genan circumscripte Gesichtsfeld-Beschränkung nach oben.

*) Arch. f. Ophth. III. 2 . p. 347.

**) I. c. p. 349-351. 
Ophthalmoskopisch: nahe der unteren Ora serrata Fremdkörper mit der Längsaxe schräg von innen oben nach aussen unten eingebettet, und zwar in der Chorioidea. Netzhaut nicht abgelöst, sondern fehlt. Da in ziemlich weitem Umfang Ecchymosen der Chorioidea vorhanden waren, konnte die Grenze des F'ehlens der Retina nur schwer bestimmt werden. Nur oberhalb in ziemlich weitem Abstande vom Fremdkörper sind abgerissene Netzhautgefissse wahrnehmbar. Es besteht ein Glaskörperopacitätenzug zum inneren unteren Linsenrand, der im vorderen Glaskörperraum eine Art häntigen Cylinder darstellt. Im Randtheil der Linse, im inneren unteren Aequator umschriebene nach hinten gerichtete Trübung, die gegen die hintere Kapsel umfangreicher ist. Kleine Iridodialyse nach innen unten, der Unregelmässigkeit der Pupille entsprechend. An der Grenze der Sclera und Cornea eine kleine lineare Narbe von 1"“, sich dem inneren unteren Hornhautrand anschliessend. Etliche Monate später waren die Chorioidealecchymosen versehwunden, oder hatten Pigmentirungen hinterlassen, besonders in der nächsten Umgebung des Fremdkörpers auffallend. Gesichtsfeldbeschränkung und Linsentrübung blieb dieselbe.

64. v. Graefe *): Patient wenige Stunden nach der Verletzung beobachtet: Unregelmässige Hornhautwunde; klaffende Iriswunde ohne Synechie; Linsenopacität und hochgradige Blutungen im Glaskörper, desshalb Fremdkörper nicht sichtbar. Nach sechs Wochen: Linsentrübung stationär; Corpus vitreum geklärt bis auf eine unscheinbare strangförmige ununterbrochene Opacität, welche sich der Linsentrübung anschliesst. Pupille erweitert und unbeweglich. Iris glänzend grün. Im Augengrund nach oben und etwas nach innen Metallstück von mindestens $2^{1 / 2}$ “ Länge und 1" Breite vollkommen nackt und stark glänzend. Mittlere Schrift mit Convexgläsern; nach unten umfangreiche Gesichtsfeldbeschränkung.

65. Jacobi*s): Patient flog ein Eisenstäck kalt gegen das Auge, und er hatte das Gefühl wie von einem Faust-

*) Arch. f. Ophth. III. 2. p. 352.

**) Arch. f. Ophth. XIV. 1 . 
schlage. Kurz darauf sieht er alle Gegenstände wie in Nebel. 1 "' nach innen vom Cornealrand im horizontalen Meridian frische feine Stichwunde der Conjunctiva sclerae. In der hinteren Hälfte des Glaskörpers eine frische Blutung, die sich ausnahm wie ein Conglomerat stark reflectirender kleiner sehwarzer Glasperlen. Leichte diffuse Trübung des ganzen Glaskörpers. Nach 3 Tagen war das Eisenfragment im Augenhintergrunde zu erkennen, die Breite auf $3 / 4 \mathrm{~mm}$ geschätzt, stahlblauer Reflex und eine Menge frischer Ecchymosen in der Retina. Ein perlschnurartiger Faden, mit Knötchen versehen, läuft durch das Corpus vitreum nach vorn zur äusseren Wunde. Dann Verschwinden der Blutflecke. Am Rande des Fremdkörpers Pigmentirung und durch ein kapselartiges Gebilde der Reflex schwächer durchscheinend. Nach weiteren 4 Tagen Blutung im Corpus vitreum, die sich bald resorbirte. Der Glaskörper markirte optisch den Weg, den der Fremdkörper genommen. Die Linse war unversehrt. Vier Monate später zeigte der Bulbus keine Abnormităt. Em. S. vollkommen. Gesichtsfeld. zeigt einen seharf umschriebenen Defect, wohl durch Ausfall der Nervenfasern, die in der Retinalwunde direct getroffen waren.

66. Hirschberg $*$ : Ein 20 jähriger Schlosser kam am 19. März 1872, um sich einen vermeintlichen Drehspahn aus der Cornea entfernen zu lassen. Das verletzte Auge liest Jäger 2, ist völlig reizlos. Eine feine Narbe von

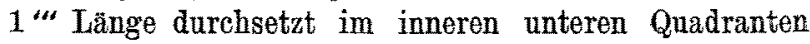
nahe dem Scleralrande die Hornhaut schräg von vora nach hinten. Dicht dahinter ist ein ebenso grosses Loch im Irisstroma. Von hier aus durehdringt eine bandförmige Trübung in axialer Richtung den Crystallkörper, der auch eine feine Unterlaufung der hinteren Corticalis erkennen lässt. Im Glaskörper sieht man ein feines Flöckchen, im Augengrunde vom Sehnerv nach unten einen kohlschwarzen zackigen Fremdkörper ron ca. 1 $1 \frac{2}{\mathrm{~mm}}$ Länge und $1 \mathrm{~mm}$ Breite, der nach Durchbohrung der Netz- und Aderhaut in der Sclera steviren geblieben ist. Drei Monate später blieb der Zustand.

*) Berl. klin. Wochenschr. 1874. No. 5. 
derselbe. Im folgenden Jahre trat zwar spät, aber doch nicht unerwartet Cataract hinzu, die demnächst operirt werden soll.

67. Nachstehender Fall ist hier eingereiht, bei welchem aber die Natur des metallischen Fremdkörpers nicht mit Bestimmtheit anzugeben ist. In der Göttinger Klinik stellte sich am 1. Angust 1871 Heinrich Schoof, 36 Jahre, Kesselschmied, vor und gab an, dass ihm beim Hämmern an einem Kessel am 16. November 1870 Etwas in beide Augen hineingeflogen sei, er empfand einen stechenden Schmerz und bemerkte eine Trübung des Sehvermögens, die sich im Verlauf der nächsten Minuten steigerte. Ein anderer Arbeiter bemerkte links etwas Blut. Acht Tage später wurde das rechte Auge in Bremen vermuthlich durch eine Linearextraction operirt. Längere Zeit Entzündung; drej Wochen nachher zählte Patient noch keine Finger, während ihm dies vor der Operation noch möglich war. Allmälige Besserung bis zum jetzigen Status. Auf dem linken Ange bestand anfangs nur geringe Sehstörung. Patient will mit diesem Auge 3 Wochen nach der Operation des rechten bei seiner Entlassung gewöhnliche Druchschrift nur etwas mühsam gelesen haben. Bald nachher, am 17. December, beim Gehen auf der Strasse plötzlich bedeutende Abnahme des Sehvermögens, worauf Patient aufs Neue in's Spital aufgenommen und mit Blutentziehungen und Zittmannsehem Decoct behandelt wurde. Keine Besserung, sondern in der ersten Zeit weitere Verschlechterung.

Status praes. R. A.: Atropinmydriasis; Aphakie; lineare Hornhautwunde gegenüber dem äusseren Pupillarrande, durch eine fadenförmige Synechie mit den Resten der Linsenkapsel verwachsen; eine feine desgleichen aminneren Pupillarrande. Ophthalm.: Am unteren Theil der Papille beginnt eine weissliche streifige Netzhauttrübung, welche sich von da längs den Gefässen nach aussen und unten zieht und in einer Entfernung von mehreren Papillendurchmessern in eine ausgedehnte weisse Stelle übergeht. Durch diese offenbar bindegewebige Trübung schimmert eine aūikie eckige Masse hindurch, möglicherweise ein abgekapseltes Corpus alienum. Die Netzhaut ist an der betreffenden Stelle zum Theil in eine Falte gelegt und 
abgelost; noch weiter nach unten lässt sich der mehrgenannte weisse Streif bis an die Grenze des ophthalmoscopischen Gesichtsfeldes verfolgen. Ausserdem erstreckt sich von der Gegend des praesumptiven Corpus alienum ein dünner weisser Strang durch das Corpus vitreum nach vorn oben, wie es scheint, in die Gegend des Ciliarkörpers. Die übrige Netzhaut seheint nicht abgelöst.

L. A. Mit Ausnahme zweier minimaler punktförmiger Trübungen im äusseren oberen Theil der Hornhaut, die ganz oberflächlich sitzen, keine Veränderung äusserlich sichtbar. Diese beiden Punkte machen nicht den Eindruck, als ob sie von einer vorhergegangenen Perforation durch ein Corpus alienum herrührten. Linse vollkommen durchsichtig. Im Glaskörper zahlreiche membranöse Trübungen, auf welchen einzelne im durchfallenden Licht vollkommen schwarze punktfôrmige Trübungen aufsitzen. Nach unten eine Anzahl intensiy weiss aussehender Trinbungen, von denen die eine, am weitesten nach unten gelegene gleichfalls den Findruck macht, als handle es sich um einen kleinen abgekapselten Fremdkörper. Im Augengrund findet sich eine ähnliche Veränderung wie die am rechten Auge beschriebene, nur weniger ausgedehnt, nach aussen unten von der Papille; es bestelit hier eine gelbweisse Prominenz mit etwas pathologiseher Pigmententwicklung, von welcher nach oben aussen ein sehnig glänzender Bindegewebsstrang in die Netzhaut hinein sich erstreekt. Vom Ende dieses letzteren strahlen eine grosse Menge feiner radiärer Streifen aus, offenbar Falten der Hyaloidea oder der Netzhaut selbst.

R. A. mit +4 Finger in $10^{\circ}$ bei excentrischer Fixation nach aussen.

L. A. mit $+24 \mathrm{~S}=\frac{15}{200^{\circ}}$. In der Nähe einzelne Worte von $17(\mathrm{~J})$.

Patient wurde vom 2.-19. August mit Injectionen von Strychninum nitricum, 0,0025-0,008, in die rechte und linke Schläfengegend behandelt.

Er las am 2. August L. No. 18, die meisten Worte von No. 17 und grosse Buchstaben von 16.

R.: Finger in 12-14'. 
4 August: L. A. mit +6 No. 9 , Worte von No. 8 in 4 " sehr mühsam. R. A. mit +2 Worte von No. 16 und 17 in $3^{\prime \prime}$.

7. August: L. A. mit +6 No. 7 und 6 . R. A. mit -2 kleine Worte von 15 und 16 mühsam.

Er klagt über periodische Verdunkelungen am rechten Auge, welche nur wenig Augenblieke dauern, und über Chromopsien in Gestalt zahlreicher gelber, blauer und grüner Flecke zur Zeit der Verdunkelung; ausserdem hat er zuweilen Aufblitzen von einem blauen Schein. Seit Anfang des Jahres will er diese Beobachtungen gemacht haben. In der letzten Zeit keine wirklichen Lichtblitze mehr.

8. August: L. A. mit +6 einzelne Worte von No. 4. R. A. mit +2 einzelne Worte von No. 13 .

14. August: L. A. mit +6 Worte von No. 2.

R. A. Status idem.

Patient localisirt die kurzen Worte, welche er entziffert, constant an einer etwas zu weit nach links unten gelegenen Stelle.

15. August: L. A. mit +4 mühsam No. 3.

19. August: R. A. mit +2 kurze Worte mühsam von No. 11.

68. Snell *): Patient G. W., 19 Jahre, hatte am 23. October 1877 eine Verletzung des rechten Auges dadureh erlitten, dass ihm beim Hämmern ein Stäckchen Stahl hineinflog. Drei Tage später sah S. den Patienten und fand ausser leichter Injection der Conjunctiva keine Entzündung, Schmerz bestand nicht. Pupille auf Atropin maximal erweitert. Medien klar. Im umgekehrten Bilde sah man wenig entfernt vom äusseren unteren Rand der Papille, einer Arterie und Vene anliegend, einen schwarzen von einer Hämorrhagie umgebenen Kōrper von metallischem Glanz, welcher als das verletzende Stahlstück angesprochen werden musste, trotzdem zverst keine äussere Wunde aufzufinden war. Die Eintrittsstelle wurde schliesslich gefunden in einer sehr feinen bereits geschlossenen Wunde der Sclera an der medialen Seite nahe dem Scleralbord. Wegen der Entzündungslosigkeit und der beinahe

\$) Ophth. Hosp. Rep. IX. p. 370 . 


\section{6}

ungestörten Sehschärfe, ferner wegen des Sitzes des Fremdkörpers wurde von jedem Eingriff abgesehen. - Atropininstillation. - Einige Tage später las Patient Jäger No. 1 und wurde ambulatoriseh behandelt. Etwa 30 Tage nach der Verletzung wurde Jäger No. 1 ohne Mühe gelesen.

Fúnf Monate später lag der Fremdkörper noch am selben Platze; die Hämorrhagie war verschwunden. Patient giebt an, mit dem einen Auge so gut zu sehen wie mit dem anderen.

69. Hirschberg ${ }^{*}$ ): Dem 29 jährigen Fabrikanten T. flog am 27. Juli 1874 beim Eisenhämmern ein Stahlsplitter in's rechte Auge. Sofort bemerkte er stechenden Schmerz; bald Röthung im Auge; der Schmerz hört nach 2 Tagen auf. Nach 6 Tagen beobachtete er beim Verschluss des linken Auges Flimmern und Schlechtersehen des rechten. Am 7. Angust wurde das Auge völlig reizfrei gefunden; $\mathrm{S}=\frac{15}{50}$, sowie mit +6 Jäger 2 in $5-6$ " bei freiem Gesichtsfeld lesbar. Der Augenspiegel zeigte mäehtige flottirende Glaskörperopacitäten. Pap. opt. leicht verschleiert; im umgekehrten Bilde nach aussen und oben von derselben eine weisse querovale Figur, worin ein schwarzer Fremdkörper steckte, der bei Drehungen des Convexglases metalliseh schimmerte. Die Narbe der Eingangsöffnung konnte nicht gleich mit Sicherheit aufgefunden werden. Nur war in der Augapfelbindehaut nach innen vom Hornhautrand eine kleine verdickte Stelle sichtbar, woselbst allein nach der Angabe des Patienten unmittelber nach der Verletzung die entzündliche Röthung beobachtet war. Dunkelzimmer, Atropin, Verband. Am 15. August wurde bei focaler Beleuchtung $5 \mathrm{~mm}$ medianwärts vom Hornhantrand und etwas oberhalb des horizontalen Meridians, hinter einer leichten Infiltration der Augapfelbindehaut eine lineare graue Narbe in der Sclera gefunden, von 11/2 $\mathrm{mm}$ Länge und annähernd horizontal gerichtet. Linse vollkommen durchsichtig; in der Mitte des Glaskörpers sehweben flockige Trübungen. Sowie Patient das Auge adducirt, sieht man den im Augengrunde festsitzenden schwarzen Fremd-

*) Berlin. klin. Wochenschr. 1875. No. 22. 
körper, Die Untersuchung im umgekehrteu Bilde zeigt die Papilla opt. und Macnla lutea unverändert. Ungefahr um 3 Papillenbreiten nach aussen und etwas nach oben rom Sehnerveneintritt ist die Vena temp. inf. auf eine kleine Strecke durch den festhaftenden Fremdkörper verdeckt, ihre Blutcirculation aber nicht unterbrochen. Der Fremdkörper ist platt, von unregelmässiger Begrenzung; der vorangehende Theil steckt fest in den Umhüllungshäuten; an dem freien nach vorn in den Glaskörper und nach oben ragenden Theil unterscheidet man eine schwarze dreieckige Fläche und eine weisse Randzone; eine ähnliche schwarze Fläche ist bei stark abwärts gerichteter Sehaxe des betreffenden Anges auf der hinteren Seite des Fremdkörpers zu sehen. Von der Mitte seiner festsitzenden Basis geht eine kleine grauliche Infiltration in die benachbarte Netzhant. Von hier aus geht nach vorn eine anfangs spitze, allmälig immer breiter werdende dünne Membran in den Glaskörper, deren optischer Querschnitt die unteren Netzhautgefässe transversal durchsehneidet. Dicht neben dem Corpus alienum nach aussen oben sieht man eine grössere Blutung im Netzhautparenchym, daneben eine kleinere. Das Ange las mit +6 Sn $1^{1 / 2}$ in $5^{\prime \prime}$ zögernd, II fliessend und zeigte keine palpable Gesichtsfeldbeschränkung. Bei mehrwöchentlicher Beobachtung wurden die Blutungen heller und hleiner, die Glaskörpertrübung zarter, das Bild des Fremdkörpers blieb unverändert.

Am 7. März 1875 liest das rechte Auge Sn. $I_{\overline{I I}}^{\frac{I}{1}}$ in 7“" durchaus sicher, wiewohl weniger rasch als mit dem gesunden. Das Gesichtsfold zeigt bei normaler Begrenzung ein nach aussen oben vom blinden Fleck gelegenes Scotom, welches der Lage und Grösse nach dem Fremdkörper entspricht. Der letztere ist noch durchaus unverändert. Der frei in den Glaskörper hineinragende Theil zeigt die früheren Contouren: einen scharfen weissen Rand und eine dunkelschwarze Fläche, in welcher eine umschriebene Stelle das ins Augeninnere geworfene licht wie ein Metallspiegel zurückwirft. An Stelle der Netzhautblutungen sieht man jetzt schwärzliche Pigmentirung, welche natürlich das Scotom vergrössem hilft. Dicht 
vor dem Corpus alienum schweben äusserst zarte helle Flöckehen im hintersten Theil des Glaskörpers. Die übrige Netzhaut ist normal; Sehnervenseheibe rosig, jedoch nicht so transparent wie im gesunden Auge.

70. Dix on *): Ein Fremdkörper hatte das obere Lid und die Selera durchschlagen; , erst nach 4 Wochen gewahrte man einen schwarzen länglichen Körper im vorderen inneren Glaskörperabschnitt. Er war mit dem Auge beweglich, und konnte von einem grossen Magneten an die Bulbuswand gezogen werden. Durch Sclerotomie wurde ein $1^{\prime \prime \prime}$ langes Stahlstúckchen entfernt. Im Glaskörper blieb noch nach $1 \frac{1}{2}$ Monat ein Strang sichtbar.

71. Noyes* ) berichtet uber folgenden Fall: Eimem 54jähr. Kaufmann war vor mehr als 2 Monaten, als er einen Nagel einhämmerte, etwas ins Auge geflogen. Es blutete etwas, wurde eine Zeit lang trübe, sehmerzte aber nicht. Das Sehvermögen war merklich herabgesetzt. Patient gab an, dass der Fremdkörper oberhalb der Cornea ins Auge geflogen sei, doch war hier keine Spur davon zu. entdecken. Cornea rolltommen klar, ohne Narbe, Pupille beweglich, etwas weiter als die andere. Linse durchsichtig und in situ; keine Synechieen. Centrales Scotom, deshalb die Sehschärfe nicht $\mathfrak{z u}$ bestimmen. Augenbintergrund deutlich sichtbar. Papille congestionirt; nach oben ersehien die Retina leicht gekräuselt oder in Falten gelegt, die Chorioidea unregelmässig, aber schwach pigmentirt. Am unteren Theil des Bulbus befand sich Netzhautablösung durch seröses Exsudat. Am auffallendsten war ein kleiner schwarzer Körper, der im Glaskörper durch einen zarten von oben nach unten ziehenden Faden aufgehängt war. Er lag in der Sehaxe und so weit nach vorn, dass er im aufrechten Bild durch eine Linse ron $+3 \frac{1}{2}$ in $1 \frac{1}{4}$ " vom Auge gesehen werden konnte. Dies war offenbar das Eisentheilchen, welches dem Patienten ins Auge geflogen war. Nach seiner Farbe zu schliessen, hatte keine Oxydation stattgefunden. Der Faden, wodurch er gehalten wurde, zeigte zweifellos den

*) Ophth. Hosp. Rep. I. p. 16.

**) Transact. of the american ophth. society VII. ann. meeting July 1870. p. 104 f. 
Lauf desselben an. Obgleich äusserlich weder eine Eintrittsstelle in der Cornea noch in der Conjunctiva oder Sclera entdeckt werden konnte, so wurde doch durch einen Pigmentfleck, welcher in der Chorioidea nahe dem Ciliarkörper am oberen Theil des Bulbus seine Lage hatte, bewiesen, dass das Metallstück hier seinen Eingang gefunden hatte, aber nicht ganz durch das Auge gefahren war, sondern seine Flugkraft beim Durchdringen der Augenhäute verloren hatte und in der Mitte des Glaskörpers hängen geblieben war. Beide Augen reizlos. Operation abgewiesen; weitere Beobachtung unmöglich.

72. Samelsohn*): Patient E. W., 19 jähriger Schlosser. Seit 3 Wochen Erblindung des linken Auges ohne Beschwerden und ohne bekannte Ursache. Stark geblähte Cataract, Iris bräunlich verfärbt und deshalb Verdacht einer Cataracta traumat. - Eintrittspforte des Fremdkörpers zuerst nicht aufzufinden, dann aber in einer ganz feinen, $1^{1 / 2} \mathrm{~mm}$ langen Cornealnarbe nachgewiesen. Lage des Corpus alienum vorläufig unbestimmbar. Modificirte Linearextraction der bräunlichen Cataract; nach derselben rom Tremdkörper nichts zu entdecken weder im Auge noch in den extrahirten Linsenmassen. Heilung in 10 Tagen völlig reizlos; $\mathrm{S}=\frac{2}{3}$. Im Auge kein Fremdlärper zu sehen. Bis Juli blieb das Auge völlig reizlos. Sehvermögen besserte sich noch etwas. 1\%/4 Jahr später war das Auge noch immer reizlos. Patient klagt über Abnahme von Sehvermögen and Photopsieen.

Man fand auf dem Boden der vorderen Kammer ein ziemlich grosses Eisenfragment fest im Iriswinkel eingekeilt; durch die Cornea gesehen, zeigte es eine unregelmässige pyramidale Gestalt mit verrosteten Bruchflächen und ca. $3 \mathrm{~mm}$ Seitenausdehnung; die Spitze der dreieckigen Pyramide schaute schräg nach innen unten. Pupillargebiet klar, noch einige braune Capselflecke im Gebiet des Coloboms in der oberen Hälfte. Mit dem Augenspiegel ausgedehnte Glaskörpertrübungen, die sehr beweglich waren.

*) Zehender's klin. Mouatsbl. f. Augenheilk. XIX. Juli 1881.

v. Graefe's Archiv für Ophthalmologie, XXVIII. 2. 
Retina und Chorioidea normal. Auge reizlos. $S=\frac{20}{200^{\circ}}$. Gesichtsfeld normal. Extractionsversuch am 31. October durch peripheren Linearschnitt. Verflüssigter Glaskörper fiel vor, in demselben Fäden von bräunlich-grüner Farbe. Extraction des Fremdkörpers misslang. Heilung nach 8 Tagen so weit, dass Lanzenwunde nach aussen angelegt wurde, um von oben her den Fremdkorper zu fassen. Auch dieser Versueh misslang wegen Glaskörpervorfall. Abermals reizloser Heilungsverlauf und Entlassung mit demselben Sehvermögen. Ohne irgend welche Veränderung wurde Patient noeh ein Jahr beobachtet.

73. B erlin *): Einem 18 jährigen Arbeiter war am 24. März 1866 ein Eisensplitter in's rechte Auge geflogen. Am: Rande der Cornea innen unten senkrechte scharfe Wunde ron $1^{1 / 2} \mathrm{~mm}$ Länge; kleiner Irisprolaps. Am Grunde des dadurch entstandenen Coloboms ist ein stark glänzender Fremdkörper sichtbar. Aussen und hinten gegen die Peripherie des Corpus vitreum einige leichte Trübungen; keine Gesichtsfeldbeschränkung. Extractionsversuch misslang, indem das Corpus alienum mehr nach unten geschoben wurde. Sehr geringe Reaction. Nach 13 Tagen entlassen mit geringer Abnahme der centralen Sehschärfe durch eine leichte diffuse Glaskörpertrübung. Nach 3/4 Jahren Sehvermögen besser; leichte strichförmige Linsentrübung von unten ausgehend. Corpus vitreum rein. Ausgebreitete Netzhautablösung bis auf die ophthalmoskopisch nicht mehr übersehbaren Retinaltheile aussen and hinten (unten?).

74. Hirschberg**): 10 jähriger Knabe, vorgestellt am 31. Mai 1877. Acht Tage vorher war ihm, während er seinem Vater einen stählernen Stab zum Behauen hielt, ein Stückehen gegen das Auge geflogen. Man sah im äusseren Quadranten der Cornea, nahe am lateralen Rand eine Trübung, von der ein grauer Streifen in den dahinter gelegenen Iristheil zog und bei focaler Beleuchtung metallisch glänzte; Pupille eng; Linse, soweit sichtbar, klar. An der Perforationsstelle geringe Injec-

*) Arch. f. Ophth. XIII. 2. p. 306 .

**) Beiträge zur prakt. Augenheilk. 1878. III. p. 91. 
tion der Conjunctiva Sclerae. Die Sehschärfe konnte wegen starken Thränens und Lichtscheu nicht gehörig bestimmt werden. Extraction des Fremdkörpers durch eine kleine Iridectomie nach aussen versucht, die aber missglüekte, weil weder der Fremdkörper extrahirt, noch später im vorderen Theil des Augapfels bemerkt wurde.

Am 6. Juni sah man einen dicken, grauen Cylinder, der den äusseren Randtheil der Linse durchsetzte und dahinter verdichtete Glaskörperopacitäten. 13. Juni Finger in $6^{\circ}$ erkannt. 20. Juli werden nach runten im Augengrund zwei weisslich bläuliche Stellen bemerkt. 9. September: $\mathrm{S} \frac{12}{200}$; Sn VII $\frac{\mathrm{I}}{\mathrm{II}}$ in $6{ }^{\circ}$. Ophthalmoskopisch ganz nach unten eine coulissenartige weisse Masse dicht vor dem Augengrund: eingekapselter Fremdkörper; daneben partielle Netzhautablösung mit einem Loch. 18. September. Ausser der partiellen Netzhautablösung bemerkte man jetzt einen scharfen Rand aus der Einkapselung des Fremdkörpers hervorragen und Bindegewebsverästelung auf der Pap. opt. Am 30. September besteht folgender Status praes.: Eine dreieckige Hornhautnarbe am lateralen Rande, an dem die Punction zur Tridectomie gemacht ist, und kleiner artificieller Irisdefect nach dieser Richtung hin. Eigenthümliche pyramidale Synechia poster. zwischen Hinterfläche der Iris und der Linse, entsprechend dem inneren Rand der Hornhautnarbe und sich fortsetzend in eine Linsentrübung, welche die linse von vorn nach hinten durchsetzt; vereinzelte Glaskörperflöckchen. Der untere Rand der Pap. opt. ist von einer Bindegewebsschicht bekleidet, welche strahlige Ausläufer in die Netzhaut sendet. Einer von diesen weissen Strahlen geht in eine Falte der Netzhautablösung über, die zuerst linienförmig, sich gegen die Peripherie hin mehr und mehr verbreitert. Nach unten sitzt in der Netzhaut ein Fremdkörper von keulenförmiger Gestalt; derselbe liegt ungefähr horizontal dicht vor der Netzhaut, sein spitziges, dabei dreikantiges weiss glänzendes Ende mit schwarzem Randstreifen steckt direct im Augengrunde da, wo die eben breiter werdende Falte der Netzhantablösung vorbeistreicht. Das laterale Ende ist von keulenförmiger Gestalt, scharfrandig und 
hat eine fixe, nur geringe Entfernung von der Netzhaut. Ein Theil des keulenfömigen Endes und die ganze mittlere Partie des Fremdkörpers ist eingehüllt in eine mächtige weisse Kapsel von schlauchförmiger Gestalt, gefässlos, am unteren Abhang mit einigen Pigmentpünktchen versehen, doch ist es nicht möglich, die periphere Grenze auch bei Mydriasis zu überschauen. Dicht oberhalb des Fremdkörpers liegen einzelne unregelmässige schwarze Fleeke in der Netzhaut.

7. December 1877 liest das Auge mit +6 D Sn 2 in 8". Gesichtsfeld nach oben defect.

75. Hirschberg*): H., 27 jähriger Arbeiter, stellt sich am 22. December 1879 vor, nachdem ihm 6 Wochen vorher beim Eisenhauen etwas in's rechte Auge geflogen war, worauf ein Bluterguss schläfenwärts im Weissen des Auges; Sehstörung und Entzündung folgte. Bei der Untersuchung äusserlich: Scleralnarbe lateralwärts: keine Injection, Medien klar. Mediale Hälfte der Papille verschleiert, wo ein bolzenförmiger Fremdkörper in der Retina festsitzt, der von einer schneeweissen Bindegewebshülle umgeben ist; der laterale Rand ragt frei als schwarze Zone vor und glänzt metallisch; umschriebene Netzhautablösung. Gesichtsfeld: blinder Fleck vergrössert und lateralwärts grosses Scotom. Mässige Herabsetzung der centralen Sehschărfe. Am 4. Januar 1880 tritt der Fremdkörper ziemlich nackt neben dem Nerrus opticus, nur mit einer weisslichen Gewebsschicht bedeckt, zu Tage; sonst ziemlich Status idem.

76. Sigel **): Einem 24 jährigen Schlosser war ein Stahlsplitter gegen das linke Auge geflogen. In der Sclera war nach unten innen, ea. $4 \mathrm{~mm}$ rom Hornhautrande entfernt, eine kleine blutunterlanfene Stelle sichtbar. Ophthalmoskop: Glaskörper leicht trüb; ganz peripher nach aussen unten, der Stelle der äusserlichen Wunde entsprechend, sieht man zusammenhängende dunkle bewegliche Körper, ohne Zweifel von der Wunde in den Glaskörper hineinragende Blutgerinnsel. Auf der inneren

*) Knapps Archiv. IX. III. Heft.

**) Nagel, Jahresber, f. Ophth. VII. 1867, S. 553. (Sigel, Inaugural-Dissertation, Tübingen.) 
Seite der Papille sieht man einen dunklen Strich, welcher, von innen oben kommend, in einem Bogen sich um die Papille wendet und nach aussen unten von ihr (zwei Papillendurchmesser entfernt) in eine dunkle bewegliche Masse endigt; hart neben dieser dunklen Masse eine scharf umschriebene blauweiss glänzende Partie: das Corpus alienum. In der Gegend der Macula ein schneeweisser Fleck; in der Netzhaut mehrere kleine Blutungen. Am Abend desselben Tages: Trübung stärker. Am folgenden Tage: Injection vermindert; Sehvermögen besser. An den nächstfolgenden T'agen: Medien vollständig klar. Am 5. Tage nach der Verletzung war die Scleralwunde geheilt und Patient ging wieder an seine Arbeit. Nach 4 Wochen: $\mathrm{S}=\frac{15}{30}$, Jäger 1 mühsam anf $18 \mathrm{~cm}$, Gesichtsfelddefect. Nach 9 Wochen stellte sich Patient wieder vor mit der Klage, dass sich das Sehen versehlechtert habe. Modien etwas trüb; Papille wie Maculagegend leicht umwölkt. Nach aussen unten hin gegen die Stelle, wo früher die dunklen Massen gelegen hatten, erstreckt sich eine weisse undeutliche Linie, noch weiter nach unten aussen sieht man zwei scharf contourirte glänzende Körper und noch weiter peripher nach dem Aequator zu zablreiche grössere und kleinere Massen, die weiss und wolkig sind und den rothen Augengrund zwischen sich lassen. Sie sehen aus wie Exsudatmassen, die in den Glaskörper hineinragen. Bei manchen Stellungen des Anges sieht man dazwischen etwas Schwarzes hervorschimmern. Von dem Metallsplitter ist an der früheren Stelle desselben nichts wahrzunehmen. Die Gegend, wo er sass, zeigt laum etwas Abnormes. Einige Tage später hatten sich die weissen Massen, welche die tiefstgelegenen Theile des Glaskörpers bedeckten, etwas gedichtet und eine schwarze Stelle kam zum Vorschein, auf welcher sich ein heller, wie Metall glänzender Fleck befand. Der Fremdkörper hatte seinen Platz geändert; auch hier blieb er nicht liegen, sondern senkte sich noch menr. Die Reizerscheinungen schwanden bald; zuletzt war $S=\frac{5}{9}$. Das Auge machte durchaus keine Beschwerden. 
77. Burgl *): Patienten Hog bei der Arbeit als Schlosser im Februar 1877 ein Stahlsplitter ins linke Auge, woranf dasselbe einige Wochen entzündet gewesen sein und die Farbe der früher hellblauen Iris sich verändert haben soll. Ein Arzt erklärte damals, dass kein Splitter sich im Auge befinde. Nach dem Ablauf der Entzündung sei das Auge völlig schmerzfrei, aber etwas sehschwächer als zuror geblieben. Patient dient als Soldat und wurde im November 1878 zufällig beobachtet. Am oberen Hornhautrand feine lineare Narbe und dahinter eine radiär gerichtete, $2 \mathrm{~mm}$ lange ovale Lïcke in der Iris, eine zweite Pupille bildend. Pupille rund, normal weit und beweglich. Gewöhnliche Druckschrift wird leicht gelesen. Auch nach Atropin keine Synechie. - Grosser glänzender Metallsplitter in der oberen Wand des Bulbus, wie das Pendel einer Uhr mittelst eines Fadens aufgehängt, das bei Bewegung Excursionen nach vor- und rückwärts ausführt. Im Glaskörper einige leicht bewegliche Flocken. Augengrund normal. Augendruck nicht merklich vermindert. Em. $\mathrm{S}=\frac{1}{4}$, Se frei, grosses bebewegliches Scotom, etwa den vierten Theil des Gesichtsfeldes einnehmend, in Ruhelage ziemlich central; offenbar der Sehatten des Splitters. Patient, als dienstuntauglieh entlassen, arbeitet weiter als Schlosser. Nach einigen Wochen heftige Entzündungserscheinungen; Thränen. Lichtscheu, rosige circumcorneale Injection. Bulbus auf Druck empfindlich; heftige Schmerzen und bedeutende Sehstörung, $S=\frac{1}{20}$. Kein Scotom mehr. Pupille auf Atropin gut erweitert; Eisensplitter abgelöst und heruntergefallen. Nach langem Suchen hart hinter den Processus ciliares gefunden. Das andere Auge thränend, acute Conjunctivitis; proponirte Enucleation kam nicht zur Ausführung, da die Beschwerden auf Atropin bald dauernd aufhörten. Das Auge zeigte äusserlich genan dasselbe Ausselien wie früher bei einer gelegentlichen Vorstellung des Patienten, drei Monate später. Am 9. Februar 1880 stellt Patient sich wieder vor, da das Auge sich von

*) Berlin. Klin. Wochenschr. 1880. No. 44. 
Zeit zu Zeit entzünde, Schmerzen mache und da er ron. der Gefahr sympathiseher Erkrankung befreit sein wolle.

Status praesens: R. A. normal. L. A.: rosige circumcorneale Injection; Bulbus schmerzhaft, Druck normal. Iris noch dunkler als früher, aber ohne entzündliche Erscheinungen. Pupille rund, sehwach beweglich, einzelne graue Flecke in deren Bereich (Auflagerungen auf die hintere Linsenkapsel), Glaskörpertrübungen; nur Finger in grosser Nähe gezählt. Auf Atropin treten oben an der Perforationsstelle und auch am Pupillarrand kleine Synechien hervor, so dass die Pupille sich nierenförmig dilatirt. Ophthalmoskopisch sieht man die erwähnten Auflagerungen an der hinteren Linsenkapsel und zahlreiche bewegliche Glaskörpertrübungen. Splitter nicht zu sehen. Am folgenden Tag, nach starker Atropinisirung, war die Injection verschwunden, Pupille etwas weiter, Auge völlig reizlos. Fremdzörper bei Sonnenlicht einen Moment gesehen und zwar beweglich.

Am 12. Februar Extraction des Fremdkorpers dureh einen Electromagneten, durch einen meridionalen Schnitt nach vorheriger Bildung eines Conjunctivallappens, der nach hinten umgeklappt wurde. Glatte Heilung nach der Operation. S wie vorher. Finger gezählt, grosse Gegenstände unterscheidbar. Zahlreiche Glaskörpertrübungen. Der Splitter hatte die Form und Grösse einer Linsenfrucht, war nur an einer ganz kleinen Stelle oberflächlich oxydirt, sonst blank. Gewicht $13 \mathrm{mg}$; er war selbst leicht magnetisch.

78. C. S. Jeaffreson *): Eisensplitter flog vor 12 Jahren ins linke Auge; Verlust von $\mathrm{S}$ nach längerem Bestehen entzündlicher Symptome. In den letzten Tagen Blutungen in die vordere Kammer ohne scheinbare Ursache. Bulbus etwas kleiner, Iris contrahirt; Pupille durch Exsudat verschlossen, kein Lichtschein. Ganz in der letzten Zeit hatte Patient unangenehme Empfindungen im Auge und das gesunde war auch irritirt. S jedoch gut; keine weitern Symptome. Die Section des enucleirten Bulbus zeigte den Eisensplitter frei am Boden des Corpus vitreum liegend, der; wie Jeaffreson glaubt, wahr-

*) Med. Times and Gazette 1874. p. 342. 
scheinlich erst vor Kurzem aus seinem Bett losgerissen war.

Was für uns diesen Fall besonders interessant macht, ist die pathologisch anatomische Untersuchung des verletzten Bulbus, welche nichts von einer Eiterung erwähnt und also in dieser Hinsicht die Annahme einer Asepsis des Fremdkorpers rechtfertigt, auf der anderen Seite aber auch die Folgen der Anwesenheit eines chemisch differenten Fremdkörpers im Inneren des Auges demonstrirt. Wir sind in der Lage, dieser Beobachtung noch drei weitere anzureihen, in denen eine möglichst sorgsame Section des Bulbus nux gewebliche Veränderungen in demselben aufzuweisen hatte, die ein Mitwirken von Keimen niederer Organismen oder deren Lebensproducten nicht wohl annehmen lässt. Wir erhalten also auch auf dem Wege der Autopsie die Bestätigung der eingangs ausgesprochenen Anschauungen. Ein bisher nur kurz erwähnter Fall aus der Gottinger Klinik *) mag zunächst hier in extenso Platz finden:

79. Karl Albrecht, Maschinenwärter, 38 Jahre, wurde in Sommer 1867 durch einen abgesprungenen Stahisplitter am linken Auge verletat, and 3 Wochen lang an den Folgen dieser Verletzung auf der chirurgischen Abtheilung des Ernst-August-Spitals in Göttingen belandelt. Die Entzündung ging durch Atropin und Eis zurück; das Auge war auch hinterher frei von Entzündung und konnte Finger zählen. Im Jahre 1869 war das Auge durch Cataracta traumatica vollständig erblindet; bemerkt ist: kleine horizontale Hornhautnarbe nach aussen vom Centrum mit vorderer Synechie; Linse cataractös, etwas bräulich gefärbt, mit einzelnen braunen Flecken auf der Oberfläche. Lichtschein gut; niedrigste Lampe sicher. Bewegungen der Hand werden gesehen.

*) Th. Leber, Ueber die Wirkung von Fremakörpern im Inneren des Auges. 1. c. p. 18. 
Am 31. Januar 1872 stellte sich Patient wegen eines leichten Epithelverlustes am anderen Auge wieder vor. Die Cornea bot jetzt ein sehr eigenthümliches Aussehen dar, wie wenn ihre ganze hintere Fläche von braunen punktförmigen Beschlägen bedeckt wäre, die Iris zeigte eine rostbraune Farbe. Patient bekam dann gegen Anfang April 1874 eine frische Entzündung am linken Auge (angeblich in Folge von hineingespritztem Cloakenwasser), welche er selbst mit Eis und zuletzt mit warmen Umschlägen behandelte. Als er sich am 13. Juni 1874 vorstellte, hatten die oben erwähnten Veränderungen noch zugenommen; die ganze Hornhaut stark diffus, feinfleckig getrübt, von braunrother Farbe, von oben her vascularisirt; kleimes Hyphaema. Pupille kaum sichtbar, nach Atropin mittelweit, nach der Hornhautnarbe hin verzogen; tiefe Injection, viel Schmorzen. Totale Amaurose. Enucleatio bulbi mit normalem Heilungsverlauf.

Die anatomische Untersuchung des schon früher im horizontalen Meridian halbirten Auges am 28. Oct. 1880 ergab Folgendes.

Nahe dem äusseren unteren Hornhantrand eine mehrere Millimeter lange winkelige Hornhautnarbe. Pupille weit; Iris zurïckgezogen, atrophisch. Linse vollständig resorbirt. Totale Netzhantablösung; Netzhaut zu einem dünnen Strang zusammengefaltet, der sich vorn etwas trichterförmig erweitert und hier nur noeh einen sehr kleinen Rest der Glaskörperhöhle einschliesst. Letztere ist leer, war also vorher mit Flüssigkeit gefüllt und nicht durch Glaskörpergewebe. Nach vorn sehliesst sich daran eine dünne Membran, vielleicht die zusammengelegte Linsenkapsel. An den beiden Bulbushälften ist auf dem Durchschnitt vom Fremdkörper nichts zu sehen. Die Chorioidea ist im vorderen Abschnitt bis hinter den Aequator dureh eine düne gallertig geronnene Flüssigkeitsschicht von der Sclera abgehoben und liegt erst hinter dem Aequator wieder an, ohne merkliche Dickenzunahme. Die abgelöste Retina mit der verdickten Zonula lüsst sich ohne Mühe vom Corpus ciliare $a b-$ trennen. Im letzteren ist ein Fremdkörper nicht zu fühlen, wohl aber fühlt man einen harten Widerstand in der abgelösten Zonula. Der Ciliarkörper erscheint auf dem 
Durehschnitt verdielit und zwar auf der lateralen Seit mehr als auf der medialen. Die untere Bulbushälfte wird nun nochmals halbirt; im hinteren Viertel ist nichts besonderes zu bemerken. Am vorderen Theil ergiebt sich, dass die hauptsächlich verdickte Partie des Ciliarkörpers sich nach aussen unten befindet, entsprechend dem Sitz der vorderen Synechie. An dieser Stelle findet sich nach einigem Suchen der Fremdkörper, ein schwarz aussehendes dünnes Eisenplättchen von ca. $3 \mathrm{~mm}$ Länge und $3 / 4 \mathrm{~mm}$ grösster Breite, dicht unter der Zonula, an dem gefalteten Theil derselben, wo sie die Abdrücke der Ciliarfortsätze trägt. Von seiner Oberfläche lässt sich leicht etwas schwarzer Eisenrost abschaben, der mit Salpetersäure und Kaliumeisencyanür die bekannte blaue Färbung giebt. In der Tmgebung finden sich zusammengebackene Blutkörper, die als solche nicht mehr deutlich zu erkennen sind; kein Eiter. Die Gegend des Circul. venos. ciliaris erscheint nach Ablösung der Iris und des Corpus ciliare von der Fläche her als braune Linie, offenbar durch Extravasat, nicht scharf begrenzt wie von Gefässen. In der vorderen Kammer ein sehr unbedeutendes Hyphaema. Die hintere Fläche der Cornea erseheint glatt und auf der Descemet'schen Membran nichts aufgelagert. Das höehst wunderbare rothbraune Aussehen der Hornhaut während des Lebens war somit nicht, wie vermuthet wurde, durch hämorrhagische Beschläge ihrer hinteren Fläche verursacht; vielmehr stellte die mikroskopische Untersuchung heraus, dass es sich um eine sehr reichliche Vascularisation und hämatogene Pigmentirung der Hornhaut handelte. Die letztere erschien auch am Präparat von rothbrauner Farbe, sehr dicht und fein grauröthlich gefleckt und völlig opak. Mikroskopiseh sieht man dicht unter der Membrana Descemetii und noch in den angrenzenden Sehichten der Hornhautgrundsubstanz ein dichtes Netz zarter, zum Theil ziemlich weiter Gefässe, dazwischen einzelne grössere Haufen von Hämatoidinkörnchen und zahlreiche von kleineren and gröberen Hämatoidinkörnehen dicht durchsetzte Zellen von unregelmässiger Gestalt. Dieselbe Veränderung erstreckt sich bis an die äussere Oberfläche, nur dass hier die Gefässe weniger zahlreich sind. 
Fast alle Zellen sind von feinen Hamatoidinkörnohen dicht erfüllt, wodurch sie ihre unregelmässig sternförmige Gestalt einigermassen zu erkennen geben.

Snell *) theilt einen ähnlichen Fall mit, in welchem der Sitz des Fremdkörpers in den Processus ciliares sich befand:

80. W. W., 50 Jahre, stellt sich im April 1875 vor und giebt an, dass ihm vor 29 Jahren ein Stückehen Stahl ins rechte Auge geflogen sei. Das Stück sei ca. ${ }^{3} / \mathrm{s}$ "lang gewesen, habe zur Hälfte im Ange gesteckt und sei ron einem Wundarzt entfernt worden. Nach ca. 2 monatlichem Leiden wurde das Auge ruhig und behielt etwa 2 Jahre lang Lichtschein. Alsdann hatte Patient ca. 20 Jahre lang weder Schmerz noch Unbequemlichkeit. Seit den letzten 9 Jahren waren im Auge, in Stirn und Schläfe äusserst heftige Schmerzen eingetreten. Die Anfülle waren mit einer Entzündung im Ange vergesellschaftet, die Patient am Arbeiten verhinderte. Die Conjunctiva war injicirt, Cornea glänzend, vordere Kammer klar, ein Theil der Iris fehlte nach unten und aussen, wie nach einer Iridectomie. Dort befand sich eine Narbe gerade neben der Verbindung von Sclera und Cornea. Auge nicht durchleuchtbar. Kein Sehvermögen oder Lichtperception. Druck normal; ebenso das linke Ange.

Enucleatio bulbi. Die Section ergab: Synchysis; Chorioidea theilweise atrophirt und in den Processus ciliares ein Stück Stahl von ca. 1/s " Länge eingelagert. Linse opak und dunkel aussehend.

Vorstehendem Falle schliesst sich eine ron $\mathrm{Knapp}$ **) mitgetheilte Beobachtung an:

81. A. I. 27. Jahre, flog im September 1875 ein Metallsplitter auf das linke Auge, durchschlug die Cornea und verwundete Iris und Linse. Einige Tage später: Cataracta traumatica. Irisprolaps in der Cornealwunde;

*) Ophth. Hosp. Rep. IX., p. 372-373.

**) Knapp's Arch. IX. III. Heft 1880 p. 227. 
Fremdkörper nicht zu sehen. Lichtempfindung gut; lrein klar nachweisbarer Sehfelddefect. Iridectomie nach obea und Extraction des grösseren Theils der Linse. Auf die Operation folgte kein grösserer Reiz. Etwas Blutung in die vordere Kammer trat auf und um den Riss in der vorderen Capsel entwickelte sich ein Ring von Blutgefässen. Während der nächsten 6 Jahre litt das Auge dannn und wann an leichten Entzündungen, die in einigen Tagen vorübergingen. Am 11. April 1879 schwere Entzündung; die Enucleatio bulbi nöthig machte (Hornhautgeschwür, Verfärbung der Iris, vordere Synechie und dichte Pupillarschwarte).

Die Section des Bulbus zeigte auf dem Aequatorialschnitt unmittelbar nach der Operation den rorderen Theil des Glasskörpers flüssig, den binteren normal. Retina und Chorioidea in normaler Lage; Sehnerv und gelber Fleck unverändert. Ungefähr $8 \mathrm{~mm}$ vom Sehnerr entfernt befand sich auf der temporalen Seite des horizontalen Meridians eine weissgraue, umschriebene, dentlich erhabene, $4 \mathrm{~mm}$ lange und $2 \mathrm{~nm}$ breite Schwarte in der Retina und unmittelbar darüber eine Vertiefung, welche an ihrem oberen äusseren Rande von schwarzem Pigment umgeben war. Im unteren Abschnitt des Auges an der Pars plicata und plana des Corpus ciliare ein längliches Metallstückchen, welches $3 \mathrm{~mm}$ lang; mit einer dünnen Bindegewebshaut bedeckt und kaum an seine Unterlage festgeheftet war. Der vordere Bulbusabschnitt zeigte die Veränderungen, wie sie sich vor der Enncleation darstellten. Suppuration bestand in dem Bulbus nicht. Derselbe zeigte das Bild frischer, plastischer Iridocyclitis.

Auch aus der Göttinger Klinik ist hier noch ein wallscheinlich hierher gehöriger Fall anzuführen:

82. August Bick, 49 Jahre, Schmied, kommt am 17. Juni 1881 in Behandlung wegen sehr schwerer Verletzung des linken Auges; quere Cornealwunde durch die ganze Breite, etwas in den inneren Theil der Selera hinein mit leichter Einklemmung der Iris, wahrscheinlich Verlust der Linse und schlechter Lichtschein. Das rechte Auge ist sehon 
seit vielen Jahren erblindet und Patient weiss über den Vorgang nicht viel bestimmtes zu berichten.

Vor ca. 25 Jahren soll ihm bei der Arbeit ein kleines Eisensplitterchen oder eine Schlacke in das Auge geflogen sein, worauf er ein bis zwei Tage lang lebhaften Schmerz verspürte; am zweiten Tage wurde angeblich von einem Arzt ein oberflächlich aufsitzender Splitter entfernt, worauf sich bald die Beschwerden vollständig verloren. Einige Jahre später flog ihm abermals beim Hämmern etwas gegen das Auge, aber wie er glaubt nur oberflächlich auf. Er achtete darauf nicht viel, bemerkte aber einige Zeit später, dass das Auge allmälig schwächer wurde, um zuletzt vollständig zu erblinden. Wie lange die Erblindung eine absolute ist, kann er nicht angeben; jedenfalls besteht hochgradige Amblyopie schon seit 20 Jahren.

Status praesens. R. A. Leichte Ciliarinjection; Iris etwas verfärbt, schlottert in ihrer ganzen Ausdehnung. Pupille mittelweit, starr. Kein Linsenreflex; tiefe Schwärze der Pupille bei geeigneter Beleuchtung wie bei Aphakie; Cornea reflectirt etwas mehr als normal. In der vorderen Kammer bei günstigem Licht ein senkrecht herabhängender Streif zusammengefalteter Linsenkapsel, der später nicht wieder bemerkt wird. Dicht neben dem medialen Hornhantrand eine kleine verticale Narbe von ca. $2^{1 / 2} \mathrm{~mm}$ Länge und dahinter eine kleine sehwarze Lücke am Ciliarrand der Iris. Pupille ophthalmoskopisch zu erlenchten; flottirende Glaskörpertrübungen nicht zu erkennen; auch kein graulicher Reflex wie, von Netzhautablösung. Papilla optici eben sichtbar, vielleicht etwas weisslich verfärbt, sonst keine Einzelnheiten zu erkennen. Beim Blick stark nach innen sieht man mit dem Angenspiegel ohne Linse zwei kleine glänzende Flecke. Augendruck nicht herabgesetzt; kein Lichtschein. Der ganze Befund erweckt den Verdacht, dass ein Corpus alienum im Auge sein möchte. Die Entstehung der absoluten Amaurose würde dann der Wirkung des Fremdlörpers zugeschrieben werden kömmen, da nach dem obigen Befund allein dafür ein genügender Grund nicht angegeben ist - sie mag auf Ablösung oder Atrophie der Retina beruhen. 
2. Juli 1881. R. A. heute wenig injicirt. Druck entschieden erhöht; Kammerwasser leicht getrübt. Iris stellenweise hyperaemisch. Papille war oben zu erkennen; das helle reflectirende Objekt noch ebenso zu constatiren. Koin Lichtschein.

Besonders grosse Fremdkörper lommen mitunter im weiteren Verlauf mit einer scharfen Ecke an einer Stelle der Bulbushüllen zum Vorschein und werden dadurch der Entfernung zugänglich, was an die Beobachtung von spontaner Ausstossung fremder Körper erinnert (vergl. die Beobachtungen von Jeaffreson auf S. 167 and die von Zander und Geissler reproducirte auf S. 194).

Ein Fall der erst genannten Art kam in der Göttinger Klinik zur Beobachtung, einen anderen theilt Castelnan mit.

83. Die Göttinger Beobachtung betraf einen 25 jührigen Kesselschmied, der sich am 18. October 1872 mit einer Verletzung des rechten Auges vorstellte. Es bestand eine penetrirende Wunde im medialen Theil der Cornea, von oben aussen nach innen unten gerichtet, welche noch mehrere Limien in die angrenzende Sclera hineinreichte; absolute Amaurose; vordere Kammer voll Blut, Pupille nicht deutlich zu sehen; wahrscheinlich ist die linse verletzt. Im inneren Theil der Wunde liegt Glaskörper vor. Bulbus etwas weich, an der Wundstelle empfindlich; von Fremdkörper nichts zu bemerken. Zwei Tage später weder Schmerzen noch entzündliche Reaction. Weiterhin mässiger Reizzustand, der nach Aussetzen des Atropins verschwand. Hierauf wurde, 34 Tage nach der Verletzung, aussen und oben auf der Scleraoberfläche eine bläuliche Stelle bemerkt, die bald stärker prominirte und den Verdacht eines Corpus alienum erregte. Mit der Sonde ist Metallhärte nachzuweisen. Es wird in Narcose daranf eingeschnitten und ein über die Oberflache der Sclera hervorragendes Fisenstïck freigelegt. Die Entfernung der Stelle des fremden Körpers rom äusseren oberen Hornhautrand beträgt ca. 8-9 $\mathrm{mm}$. Erst nach ausgiebiger Erweiterung der bestehenden 
Oefinung der Sclera gelang die Entfernung des Fremdkörpers, der sich als ein $22 \mathrm{~mm}$ langes, $11^{1 / 2} \mathrm{~mm}$ breites plattes Eisenstück herausstellte. Der Körper musste von unten innen nach oben aussen ins Auge eingedrungen sein und die gegenüberliegende Sclera znm zweiten Mal perforirt haben, da die Extractionswunde weit von dem Rande der ursprünglichen Eintrittsstelle entfernt war. Im Anfang konnte die Gegenwart des Corpus alienum nicht nachgewiesen werden; Patient versicherte sogar, dass es aus dem Auge herausgefallen sei. Nach 8 Tagen war die Heilung obne Reaction vollendet und Patient wurde entlassen.

84. Castelnau*): Einem Werkmeister in einer Eisenbainwerkstätte Hlog am 29. Juni 1838, als auf Eisen gehämmert wurde, etwas ins Auge; es floss Wasser $a b_{\text {; }}$ und Patient fühlte einen heftigen andauernden Schmerz. Ein Arzt fand Perforation der Cornea und behandelte den Patienten mit Blutegeln, einer Salbe und kalten Umschlägen einen Monat. Dann vernarbte die Cornealwunde; Röthung und Schmerzen minderten sich und Patient arbeitete wieder. Er unterschied damals noch Tag und Nacht, aber der Lichtschein verminderte sich fortwährend und nach 18 Monaten war totale Amaurose eingetreten. Es vergingen zwei Jahre ohne irgend welche Beschwerden; dann änsserst heftiger Schmerzanfall von 4 . Tagen, auf welchen wieder eine Periode von Wohlsein bis Ende Februar 1842, d. h. 31/2 Jahre nach der Verletzung, folgte.

Als C. den Patienten sah, war die Conjunetiva wenig geröthet; die Cornea war getrübt und zeigte beinahe im Centrum eine konische Hervorragung; der Bulbus salz aus wie ein Auge, welches Mlussigkeit verloren hat. Patient hatte starke Schmerzen und konnte nur anf der rechten Seite liegen. Eis, Belladonnasalbe, SenfFussbäder - keine Erleichterung, Vermehrung der Rothe. Nach einigen Tagen erschien auf der Hervorragung die Ecke eines barten Gegenstandes, der als Fremdkörper erkannt wurde. Extractionsvorschlag abgelehnt; am 6. März 1842 war der Fremdkörper weiter

*) Arch. gén. de méd. 1842. Tom, XV., p. 210. 
herausgetreten und ulcerirte die Conjunctiva tarsi. Die Cornea zeigte keine Eiterung. Die Operation wurde nun versucht. Der Fremdkörper war mit der Umgebung innig verwachsen; der Zug bereitete grosse Schmerzen. Durch die Scheere wurden die Adhärenzen getrennt und ein Eisenstïckchen entfernt von prismatischer Gestalt, scharfen Rändern, $30 \mathrm{~mm}$ Länge, $5 \mathrm{~mm}$ Breite, von einem. Gewicht von 65 etg.

Nach der Operation Nachlass der Schmerzen; 4 Tage später arbeitete Patient wieder. Cornea opak; die Stelle der Extraction beinahe verstrichen. Keine Eiterung.

\section{b) Kupfer.}

85. Sigel*): Nach einer Zündhütchenverletzung schmerzte das Auge nur im Moment der Verwundung, thränte und Sehvermögen nahm ab. Aeusserlich nichts Abnormes. In der Gegend der Macula lutea sieht man einen scharf umschriebenen, unregelmässig eckig gestalteten, mit hellgelber Farbe intensiv metallisch glänzenden Fleck, unverkenubar dás eingedrungene Metalfragment. Die näehste Umgebung ist dunkler als der Augengrund. Das Gesichtsfeld zeigt nahe dem Fixirpunkt einen Defect. Reizbarkeit binnen wenigen Tagen beseitigt. Sehvermögen blieb $5 / 18$. Mehrere Monate lang hatte sich der Zustand ganz unverändert erhalten.

86. Schelske ** beobachtet seit drei Jahren ein Körperchen in der Netzhaut, mit einer Risswunde, welches mit Ausnahme eines geringen Sehfelddefectes für die Function des Organes vorläufig keine üblen Folgen gehabt hat, nachdem ein beschränkter entzündlicher Process zur Rnhe gekommen ist. Fin Zündhutsplitter traf das Auge, durchbohrte punktförmig die Cornea central, schlug in Kleiner strahlenförmiger Narbe durch die Linse, durchbohrte ohne zurückbleibendes Zeichen den Glaskörper und sching in die obere nasale sehr periphere

*) Nagel, Jahresber. f. Ophth. VII. 1876. S. 554. (Sigel, Inaugural-Dissertation.)

**) Schelske, Lehrbuch der Augenheilkunde. Berlin 1869. pag. 205 . 
Netzhantpartie ein, so dass diese eine rechtwinklige Wunde empfing mit geschwellten, das Licht sehr stark reflectirenden Rändern, in deren Tiefo die Chorioidea ohne merkbare Verletzung unbedeckt sicbtbar war. Der Metallsplitter fuhr dann noch eine Strecke zwischen sehr partiell abgelöster Netzhaut und Chorioidea weiter, blieb nun etwas um seine Axe gedreht sitzen und präsentirte sich dort als ein glänzend schildförmiges Plättehen von einem leicht getrübten Retinatheilchen gedeckt, das mit einer kleinen strichförmigen Falte mit der oberen Wundecke zusammenhing. In der freiliegenden Chorioidea entstand nun im Verlauf mehrerer Monate eine Veränderung, welche bewirkte, dass ein Theil derselben mehr und mehr mit dichtem schwarzen Pigment gedeckt ward, während die Nachbarstelle eine weisse atrophische Fläche bildete, welche die Sclera unverhüllt durchscheinen liess. Die Ränder der Retinawnde verloren die Schwellung und glichen einer einfachen. Continuitätstrennung; auch jener kleine, Wundecke und Splitter verbindende Faden schwand. Das Metall unter dem beschriebenen Wolkchen hat seinen Glanz und seine Lage bewahrt. In diesem Zustand beharrt das Auge nun seit zwei Jahren. Trotzdem bleibt der Fremdkörper ein gefährlicher Besitz und muss auf plotzlich auftretende entzündliche symptome gefasst machen.

87. Schwarzbach*): Verletzung durch eín Zündhutstück, das einem 10jährigen llädchen ins Auge geflogen war; der Gang des Fremdkörpers war folgender: Er drang an der Hornhautperipherie aussen und oben ein, riss den pupillaren Theil der Tris ein und ging in axialer Richtung durch die Linse. An der Oeffnung in der hinteren Capsel sieht man zahlreiche Glaskörpermembranen haften. Das anfangs sehr redueirte Sehen besserte sich mit Aufhellung der Glaskörpertrübungen. Man sieht nicht weit hinter der Linse einen metallenen Körper liegen, welcher sich nach einiger Zeit ( $1 / 4 \mathrm{Jahr})$ einzukapseln beginnt.

88. Pagenstecher ${ }^{*}$ ) erwähnt als Ausnahmefall, dass ein

*) Arch. f. Augen- u. Ohrenheilk. V. 2. p. 32 ff.

*\%) Sitzber. d. ophth. Ges. 1869. Zehender's M. Bl. I., p. 449.

v. Graefe's Archiv für Ophthalmologie, XXVIII. 2. 
Stück Zündhütchen 3-4 Jahre lang in den tieferen Theilen des Auges verweilt und erst dann zur Entzündung geführt habe.

89. Hirschberg*): H. P., 20 Jahre, stellt sich an 25. November 1879 vor; im Jahre 1866 war das rechte Auge durch einen Zündhütchensplitter verletzt und angeblich der Fremdkörper extrahirt. 1877 fand eine Iritomie statt. Seit einem halben Jahre bestand hartnäckiges Flimmern. Linkes Auge myopisch, M - $4 \mathrm{D}$, S. $\mathfrak{n}$; rechtes Auge amaurotisch; keine Entzündung Strabismus divergens, künstliche Pupille, Aphakie und Netzhautablösung; vor dieser ein bläulichschimmernder Körper. Enucleation.

Section des Bulbus ergab: Synchysis, trichterförmige Netzhautablösung; klaffender Schnitt durch die Linsenkapsel. In der medialen Bulbushälfte, $12 \mathrm{~mm}$ rom nervus opticus ein Metallsplitter, der die Netzhaut und Aderhaut gewissermassen an die Sclera festnagelt. Splitter platt, dünn, fast ganz ron einer weissen Schicht überzogen, nur an einer Kante schwärzlich. Aderhant nur in geringer Ausdehnung mit der Sclera verwachsen, am Aequator leicht abgelöst.

90. H. D. Noyes $\left.{ }^{* *}\right)$, Cases of foreign bodies in the vitreous humor; case II. 21 jähr. Mann; Verletzung durch einer Zündhutsplitter beim Abfeuern eines Gewehrs. Sofortige Erblindung. 3-4 Wochen lang Entzündung, die einige Zeit nachher nochmals für eine Woche recidivirte; später nur $a b$ und zu rasch vorübergehende Schmerzanfälle. 16 Monate nach der Verletzung subjective Lichterscheinungen und accommodative Asthenopie. Form und Spannung des Auges normal. Im inneren oberen Theil der Cornea 1 " " lange Narbe. Vordere Kammer tief, Linse resorbirt, Pupillenrand mit den Kapselresten stellenweise adhärent; Iris unverändert. Die Mitte der Pupille vollkommen frei, Augengrund nur schwach zu erhellen, aber beim

*) Knapp's Archir IX. 3., p. 313-314.

**) Transact. of the Amer. ophth. Soc. VII. ann. meeting 1870. p. $105-108$. 
Blick stark nach unten ein hellgelb metallisch glänzender Fremdkörper, beweglich im Corpus vitreum zu sehen. Quantitative Lichtempfindung im äusseren unteren Theil des Gesichtsfeldes.

Die Untersuchung des enucleirten Bulbus bestätigte die Diagnose des Kupferstückchens im Glaskörper; nur erwies sich die Netzhaut nicht abgelöst, wie angenommen war, sondern es fand sich totale Ablösung des Glaskörpers mit leichter Verdichtung desselben; der Fremdkörper sass im Corpus vitreum in der Gegend der Ora serrata. Er musste wohl das Auge bis zur gegenüberliegenden Wand durchschlagen haben, da abgeprallt und auf den Boden des Glaskörpers heruntergefallen sein. Die Enucleation beseitigte vollständig die sympathischen Reizerscheinungen.

Es ist dieser Fall hier aufgenommen, obwohl die Verletzung anfangs von Entzündungserscheinungen gefolgt war; das Verhalten des Auges scheint zu beweisen, dass diese nur die Folge der Verletzung, insbesondere der Linse waren, und dass keine Infection stattgefunden hatte. Andernfalls würde eitrige Exsudation und Pupillarverschluss eingetreten sein, anch hätte der Fremdkörper nicht so frei und ohne einhüllende Exsudation oder Einkapselung im Glaskörper verbleiben können. Die sympathischen Reizerscheinungen erklären sich in der oben besprochenen Weise, sei es durch die mechanische oder chemische Reizung, die von dem Fremdkörper ausging.

In nachstehendem Falle aus der Göttinger Klinik, wo ein Kupferstuckchen frei in der Gegend des Corpus ciliare im Glaskörper sass, beschränkten sich die Erscheinungen auf wiederkehrende Injection und mässigen Reizzustand 4 Wochen nach der Verletzung, so dass ein dauerndes Vertragenwerden des Fremdkörpers nicht zu hoffen war. Obwohl die Entfernung desselben gelang und die Operation nicht von Entzundung gefolgt war, konnte doch kein Sehvermögen erhalten werden, da der Eingriff der Operation 
selbst zu erheblich war und wahrseheinlieh durch innere Blutung Ablösung der tieferen Membranen erfolgte.

91. Der Fall betrifft den 30jährigen Aug. Becker aus Lauter* berg. Derselbe stellt sich am 19. März 1880 vor, nachdem er sich am linken Auge am 11. October 1879 beim Hämmern auf ein Eisenstück verletzt hatte. Er glaubt nicht, dass ein Metallsplitter eingedrungen sei und es war die Constatirung eines solchen naeh dem Bericht des behandelnden Arztes nicht möglich wegen intraocularen Blutergusses. Erhebliche Entzündung scheint auf die Verletzung nicht gefolgt zn sein und nach Resorption des Extravasates soll einige Zeit darauf, nach innen zu, in der Tiefe der Pupille, der auch jetzt in gleicher Weise zu bemerkende Fremdkörper zum Vorschein gekommen sein. Das Auge blieb seitdem völlig reizlos und auch das Sehvermögen war nur wenig gestört; erst im Januar 1880 stellte sich für 14 Tage etwas Entzündung ein, dem Berichte nach entzündliche Roizung des Ciliarkörpers, welche sich auf Atropininstillation und Schonung bald wieder verlor. Am 15. März 1880 wurde aus der Narbe ein kleines schwarzes Pünktchen entfernt, ohne dabei auf einen Fremakörper zu stossen.

Status praesens. L. A.: Andeutung von oberflächlicher Ciliarinjection; neben dem inneren Hornhautrand, nngeführ im horizontalen Meridian verlaufend, eine ca. $3 \mathrm{~mm}$ lange Seleralnarbe; Iris leicht grïnlich (am rechten Auge blau). Pupille auf Atropin maximal erweitert; bei schrägem Einblick bemerkt man schon bei Tageslicht weit nach innen, dicht hinter und neben der linse, im horizontalen Meridian ein eckiges kupferfarbenes Metallstüekchen, welches etwas schief gerichtet ist. In Bezug auf die Natur desselben ist zu bemerken, dass Patient bei der Verletzung nur mit Eisen arbeitete, dass aber doch die Möglichkeit nicht ausgeschlossen ist, dass ein von einer vorhergehenden Arbeit mit Kupfer liegen gebliebenes Stückchen durch den Schlag getroffen und ins Auge gesprungen war. Hinter der Linse bemerkt man überdies zarte membranöse, leicht flottirende Opacitäten, deren inneres Ende in der Gegend der Verletzung mehr fixirt scheint; überdies eine eigenthümliche 
zarte radiäre Streifung, die nach dem Linsenrande hin convergirt und den Eindruck macht, als handle es sich um eine Faltung der hinteren Linsenkapsel. Augengrund normal. $\mathrm{s}=\frac{20}{2 v}$, No. 1. L. A. mit $-1 \mathrm{D}$ $\mathrm{S}=\frac{20}{200}$, mit $+6 \mathrm{D}$ No. 1.

In Anbetracht des guten Sehvermögens wird ein Extractionsversuch vorläufig verschoben.

9. April 1880. Status idem. Patient hat unterdessen wieder einen Anfall von Eutzündung am linken Auge gehabt, der übrigens rasch zurückging; objectiver Zustand ziemlich unverändert; das Metallstückchen vollständig blank zu sehen; die umgebende Glaskörpertrübung vielleicht etwas ausgedehnter. Die Falten der Zonula mehr hervortretend, straff gespannt und der ganze dem Aequator benachbarte Theil der hinteren Corticalis in höchst eigenthümlicher Weise spiegelartig glänzend.

15. April 1880. Operation zur Entfernung des Fremdkörpers in Narcose. Da derselbe seinem Aussehen nach sicher als Kupferstückchen anzusehen ist, was sich auch nach der Extraction bestätigt, so kann von einem Versuch mit dem Magneten abgesehen werden. Es wird zunächst in der Gegend der vom Eindringen des Fremdkörpers herrührenden Scleralnarbe, medialwärts von der Hornhaut, ein ca. $5 \mathrm{~mm}$ breiter Conjunctivallappen gebildet, der nach der Hornhaut zu zurückzuklappen war; alsdann, nach Freilegung der Sclera, ein horizontaler Lanzenschnitt ca. $1,5 \mathrm{~mm}$. unterhalb der horizontal verlaufenden Seleralnarbe angelegt. Der Fremdkörper stellt sich nicht ein; es wird daher von dem Ende des Lanzenschnittes, welches rom Hornhautrande abgewendet ist, senkrecht zu dessen Richtung, parallel dem inneren Hornhautrand ein verticaler Scheerenschnitt nach oben gefuhrt, so dass auch in der Sclera ein nach immen aufzuklappender Lappen entsteht. Auch jetzt ist ein Corpus alienum weder durch die Scleralwunde noch durch die Cornea sichtbar. Letztere ist inzwischen collabirt, faltet sich und es ergiesst sich etwas Blut in die vordere Kammer. Vorsichtiges Sondiren und Eingehen mit dem Dariel'sehen Löffel hat ebenso wenig Erfolg. In der 
Wunde zeigt sich nur Aderhaut und verdichtete Glaskörpersubstanz. Es bleibt nichts übrig, als mit Häkchen und der Pinzette das verdichtete Gewebe hervorzuziehen nnd abzutragen. Nachdem dies zu wiederholten Malen geschehen, kommt endlich der Fremdkörper zum Vorschein und kann mit der Pincette gefasst und extrahirt werden. Derselbe erweist sich als ein sehr dünnes Kupferplättchen von fast $4 \mathrm{~mm}$ Länge und $2 \mathrm{~mm}$ grösster Breite, das auf der einen Seite schwärzlich angelaufen ist, auf der anderen zum Theil roth metallisch glänzt.

Trotz der sebr eingreifenden Operation exfolgte bei antiseptischer Wundbehandlung die Heilung olne jede entzündliche Reaction; leider aber war, offenbar durch intraoculare Blutung, das Selvermögen bis auf einen geringen Rest erloschen und stellte sich auch weiterhin nicht wieder ein.

Am 25. April 1880 ist die Wunde gut geschlossen, Injection nur noch sehr mässig, kein Reiz. Der Augendruek leicht herabgesetzt.

Pupille bei wenig Atropin mittelweit mit, einer hinteren Synechie; Kammerwasser ein wenig trübe. Heller Reflex ans dem Glaskörper. Linse durchsichtig. Bewegung der Hand nur unsicher wahrgenommen.

3. Mai 1880. Wunde vernarbt; nur noch in ihrer näheren Umgebung Injection. Pupille auf Atropin mittelweit ohne Synechieen. Iris noch grünlich verfürbt. Augendruck sehr herabgesetzt. Gelber Reflex bei Tageslicht und focaler Beleuchtung; davor zarte Falten die nach der Gegend der Narbe hinziehen. Keine Linsentrübung. Augengrund nicht zu erleuchten. Nor unsicher Bewegungen der Hand zu erkennen; Lichtschein ziemlich niedrigste Lampe. Projection gut.

5. Mai 1880. Bewegungen der Hand viel sicherer, sonst Status idem.

17. Mai 1880. Bulbus noch ziemlich weich. Glaskörper etwas aufgehellt, von innen her ist eine gelbliche Masse zu sehen, die bei Bewegung des Auges leicht flottirt, und bei focaler Beleuchtung sieht man zarte Falten, straff nach der Gegend der Narbe hin gespannt. $\mathrm{Ob}$ die gefaltete Masse nur verdichteter Glaskörper oder auch abgelöstes Corpus ciliare ist, lässt sich nicht ent- 
scheiden. Nach den anderen Seiten noch kein rothes Licht zu erhalten. Finger in ca. $1^{\prime}$ gezählt, Bewegungen der Hand excentrisch wahrgenommen, jedoch nicht lateralwärts.

27. Juni 1880. L. A. Bindehaut nur im Bereich der Narbe ein wenig geröthet. Angendruck noch etwas herabgesetzt. Iris kaum merklich verfärbt, vollkommene Atropinmydriasis. Die gelbe Masse im Glaskörper verkleinert und mehr in einzelne Abtheilungen getrennt. Dafür tritt die radiäre Streifung binter der Linse, aus nach der Narbe hin convergirenden Zügen bestehend, noch viel deutlicher hervor und erstreckt sich auf eine grosse Ausdehnung. Die Linse ist nach innen unten verschoben, so dass bei schrägem Einblick ihr änsserer oberer Band neben dem der Pupille sichtbar wird. Zagleich ist sie derart um ihre Axe gedreht, dass ihr ihr innerer unterer Theil die Iris nach vorn drängt; sie erscheint jetzt ganz leicht diffus getrübt. Augengrund. im Allgemeinen nur wenig zu erhellen; rothes Licht erhält man nur bei schrägem Einblick neben der linse vorbei.

Finger gezähit excentrisch nach innen unten.

Die zahlreichen hier zusammengestellten Fälle bestätigen für den Glaskörper und seine Wandungen vollauf die bei dem Sitz im vorderen Abschnitt des Auges gemachte Erfahrung, dass auch bei Fremdkörpern aus oxydablen Metallen, wofern sie aseptisch eingedrungen sind, acute eitrige Entzündung ausbleiben kann.

In einer Reihe von Fällen wurden auch hier sowohl Eisen- als Kupfertheilchen, sei es im Glaskörper suspendirt, sei es im Augengrund festsitzend, lange Zeit hindurch ohne alle Beschwerde ertragen und ohne grössere Sehstörung hervorzurufen, als von der etwaigen Trübung des Glaskörpers oder der Linse abhängig war. Die längste Zeit eines solchen inoffensiven Verhaltens berichten Soelberg-Wells (2 Jahre) und Jäger (3 Jahre) von Eisen, 
und Pagenstecher (3-4 Jahre) von Kupfer; in allen anderen Fällen finden wir dagegen, dass im weiteren Verlauf noch sonstige Veränderungen auftreten, bald mit, bald ohne subjective oder objective Entzündungserscheinungen. Unter diesen ist vor allem Netzhautablösung zu erwähnen, die unter ganz eigenthümlichen Umständen entsteht. Es ist wohl bekannt, dass von einer die Augenhäute durchsetzenden Narbe aus in Folge von Bindegewebsretraction und Anzerrung der benachbarten Theile sich Ablossung dieser Membran entwickelt; in den hier vorliegenden Fällen kann aber eine solche Narbe ganz fehlen, indem der Fremdkörper durch Hornhaut und Linse eingedrungen war; andere Male ist die Narbe so geringfügig oder derart localisirt, dass die Netzhautablösung gar nicht von ihr abgeleitet werden kann. Nach Maassgabe der Versuche von Prof. Leber, welcher bei im Glaskörper suspendirten Eisen- oder Kupferstückchen unter seinen Augen mehrmals Netzhautablösung entstehen sah, ist wohl auch hier die Netzhautablösung in gleicher Weise zu erklären; der Fremdkörper scheint durch seine chemische Wirkung eine Verdichtung des Glaskörpers zu Stande zu bringen, welche die Netzhant nach sich zieht. Besonders schlagend sind hier wieder die Falle, wie ein von Noyes mitgetheilter (p. 208), wo der Fremdkörper gar nicht die Wandungen des Glaskörpers berührt, sondern in demselben an einem zarten Fädchen suspendirt bleibt and wo es gleichwohl zur Ablösung der Retina kommt und zwar nicht bloss an dem dem Zug des Fremdkörpers entsprechenden oberen Abschnitt, sondern auch in der unteren Hälfte, wo jene mechanische Wirkung gar nicht zur Geltung kommen kann. Mitunter kann sich die Schrumpfung auch auf den Glaskörper beschränken, ohne dass die Netzhaut nachgezogen wird, und es entsteht sodann Glaskörperablösung, indem der durch die Schrumpfung frei werdende Theil mit serösem Transsudat erfüllt wird, wie 
in einem zweiten Fall von Noyes bei einem Kupferstückehen (p. 226).

Prof. Leber fand bei seinen Versuchen an Thieren in der Umgebung des Fremdkörpers das Glaskörpergewebe eigenthümlich braun oder grünlich braun gefärbt; es ist interessant, dass etwas ähnliches anch von Samelsohn (S. 209) beim Menschen beobachtet wurde. Es handelt sich um den Fall, wo der in dem Kammerwinkel sitzende Fremdkörper bei zwei Extractionsversuehen zurückgelassen werden musste, weil jedesmal bei dem Schnitt reichlicher Ausfluss von Glaskörperflussigkeit folgte, in welcher grünlich - braune Fäden suspendirt waren; man möchte demnach vermuthen, dass der Fremdkörper irgendwie mit dem Glaskörper in Berührung war. Glaskörpertrübungen in der Umgebung des Fremdkörpers finden sich überhaupt sehr häufig angeführt, doch ist ihre Deutung im einzelnen Falle nicht immer sicher zu geben. Sie können theils hämorrhagiseher Natur sein, theils hie und da bei Verletzung der hinteren Linsenkapsel von in den Glaskörper vorgequollener Linsensubstanz herrühren, theils der chemischen Wirkung des Fremdkörpers auf das Corpus vitreum ihre Entstehung verdanken.

Sehr bemerkenswerth sind die Erscheinungen, welche durch Lageveränderung des Fremdkörpers hervorgerufen werden. Ein innen in den Bulbushüllen fixirter Fremdkörper kann sich ablösen und an den Boden des Glaskörpers herunterfallen, wo er durch seine mechanische Einwirkung Schmerzen macht, die sehr lebhaft und unerträglich sein können, häufig recidiviren, auch sympathische Reizung des anderen Auges nach sich ziehen. Ueberdies kann durch die mechanische Wirkung die Retina secundär verletzt, wohl auch zn Blutungen Anlass gegeben werden. Aehnliche Vorgänge treten bei der Senkung eines im Glaskörper suspendirten Corpus alienum auf. Nicht besser kann aber gezeigt werden, dass blosse mechanische Ein- 


\section{4}

wirkung keine eigentliche Entzündung nach sich zieht, als durch die Erfahrung, wie gut das Auge solche Eingriffe übersteht, und wie es sich nach denselben wieder vollkommen erholen kann, ohne dass es zu entzündlicher Exsudation gekommen ist.

Nach Jahre langem Verweilen des Fremdkörpers kann es zu totaler Netzhautablösung kommen, wobei der Glaskörper vollkommen verschwindet, aber ohne dass das Auge dabei phthisisch wird und ohne dass es wie bei der gewöhnlichen secundären Netzhautablösung durch plastische Cyclitis in Folge von Trauma zur Entwicklung von Bindegewebsschwarten an der Innenfläche des Ciliarkörpers kommt, wie durch den Sectionsbefund des Falles Albrecht (p. 216) bewiesen wird. Sehr merkwürdig und ungewöhnlich waren in diesem Falle anch die recidivirenden Blutungen in die vordere Kammer und die Vascularisation und hämatogene Pigmentirung der Cornea. Frst weitere Beobachtungen können die Vermuthung prüfen, ob auch diese Veränderungen als Folge der chemischen Einwirlung gelten dürfen.

Wenn in manchen Fällen, wie z. B. in dem ron Knapp (p. 219) mitgetheilten, als Folge der Einwirkung des Fremdkörpers plastische Cyclitis angeführt wird, so können wir diese nicht als beweisend ansehen, wenn andere mögliche Ursachen der letzteren nicht mit einiger Wahrscheinlichkeit ausgeschlossen sind. So beweist z. B. in dem Knapp'schen Fall das Vorhandensein von totalem. Pupillarversehluss, dass bereits die früher gemachte Iridectomie von stärkerer entzündlicher Exsudation gefolgt war und das zuletzt aufgetretene eitrige Hornhautgeschwür kann doch unmöglich der Wirkung des im Glaskörperraum eingeschlossenen Fremakörpers zugeschrieben werden.

Zum Sehluss hätten wir noch der Fälle zu gedenken, wo ein aseptiseher Fremdkörper von ungewöhnlicher Grösse im Auge einheilt, aber später zur Elimination tendirt und 
durch von ihm verursachte Beschwerden Anlass zur Entfernung giebt, wie in dem in der Göttinger Klinik beobachteten Fall und in dem von Castelnau, in welchem das betr. Eisenstück einen Durchmesser von 22:8-9 mm resp. von $32: 5 \mathrm{~mm}$ hatte. Nur ein aseptisches Verhalten kann ein so langes Bleiben des Fremdkörpers von 34 Tagen, resp. $3^{1 / 2}$ Jahren im Auge erklären; Sehmerzen und Injection sind der mechanischen Reizung zuzuschreiben; was von Retinafunction etwa noch den ursprünglichen Eingriff der Verletzung überstanden hatte, wird theils durch die fortdauernden mechanischen Einwirkungen, theils durch die bei der Grösse des Fremdkörpers auch nicht unerhebliche chemische Wirkung desselben bald verloren gehen müssen, so dass absolute Amaurose folgt. Die mit der Zeit eintretende Verkleinerung des Bulbus führt dann dazu, dass der Fremdkörper irgendwo die Hüllen hervortreibt, wohl meist an einer Stelle, wo schon bei der Verletzung eine Perforation stattgefunden hat, was dann zur Entdeckung seiner Anwesenheit und zur Extraction Anlass giebt.

Ueberblicken wir nochmals die vorstehenden Erorterungen, so können wir sagen, dass uns unsere Untersuchungen an dem casuistischen Material der Verletzungen am menschliehen Auge zu Ergebnissen geführt haben, welche mit den theoretisehen Voraussetzungen und den Versuchen an Thieren in sehr guter Uebereinstimmung sind.

Fragen wir zuletzt, welehen Einfluss die hier gewonnenen Erfahrungen auf unser practisches Verhalten haben können, so wird zwar in dieser Hinsicht noch grosse Zurückhaltung geboten sein, doch dürften nach denselben die bisher in der Praxis massgebenden Grundsătze wohl keine sehr erhebliche Aenderung erleiden. Mögen wir noch so sehr von dem infectiossen Ursprung der traumatischen Entzündungen überzeugt sein, so wird uns dies 
in der Mehrzahl der Fälle von Fremdkörpern im Innern des Auges doch nicht daran irre machen, wie bisher die Entfernung derselben aus dem Auge auch in solchen Fällen anzustreben, wo keine septische Complication anzunehmen ist. Eisen- und Kupferstückchen können bei längerem Verweilen dem Auge höchst gefährlich werden, auch wenn nur ihre Wirkung für sich allein in Betracht kommt, und auch wenn es nicht zum Auftreten eitriger Entzündung kommt.

Da aber ihre schädlichen Folgen sich oft erst langsam and allmälig einstellen, so ist meistens keine Eile geboten und man wird sich, wie man dies auch bisher zu thun pflegte, von dem jedesmaligen Verlauf des Falles in seinem Handeln bestimmen lassen dürfen. Ein noch so langes unschädliches Verweilen im Auge darf uns aber nicht sicher machen; denn die Erfahrung hat gezeigt, dass manche Augen an den in ihnen enthaltenen Fremdkörpern erst nach vielen Jahren zu Grunde gehen. Unbedenklich dürfte es dagegen sein, chemisch ganz indifferente Fremdkörper im Auge zu lassen, wenn eimmal die erste Zeit ohne infectiöse Entzündung vorüber gegangen ist, in sofern nicht etwa späterhin die rein mechanische Irritation bei seharfen Ecken oder Spitzen des Fremdkörpers trotzdem zur Entfernung nöthigt.

Was endlich die Möglichkeit der Betheiligung des zweiten Auges anlangt, so sind wir zu der Ansicht gekommen, dass bei vollkommen aseptischen Fremdkörpern las zweite Auge nur unter der gutartigen Form der sympathischen Reizung erkrankt, nicht aber von echter sympathischer Entzündung ergriffen wird. $\mathrm{Da}$ die erstere Affection durch Entfernung des erst erkrankten Auges stets vollkommen beseitigt werden kann, so dürfte bei dieser Art von Fremdkörperverletzung die Gefahr für das zweite Auge sich als wesentlich geringer herausstellen als man dies bisher für gewöhnlich anzunehmen geneigt war. 